University of San Diego

Digital USD

2011-05-01

\title{
Tapping the Hidden Job Market through Informational Interviews: A Qualitative Examination of Students' and Professionals' Perspectives
}

Kimberly S. Hogelucht PhD

University of San Diego

Follow this and additional works at: https://digital.sandiego.edu/dissertations

Part of the Leadership Studies Commons

\section{Digital USD Citation}

Hogelucht, Kimberly S. PhD, "Tapping the Hidden Job Market through Informational Interviews: A Qualitative Examination of Students' and Professionals' Perspectives" (2011). Dissertations. 825. https://digital.sandiego.edu/dissertations/825

This Dissertation: Open Access is brought to you for free and open access by the Theses and Dissertations at Digital USD. It has been accepted for inclusion in Dissertations by an authorized administrator of Digital USD. For more information, please contact digital@sandiego.edu. 
TAPPING THE HIDDEN JOB MARKET THROUGH INFORMATIONAL INTERVIEWS:

\title{
A QUALITATIVE EXAMINATION OF STUDENTS' AND PROFESSIONALS' PERSPECTIVES
}

\author{
By \\ Kimberly S. Hogelucht \\ A dissertation submitted in partial fulfillment \\ Of the requirements for the degree of \\ Doctor of Philosophy \\ University of San Diego
}

May 2011

Dissertation Committee

Lea Hubbard, Ph.D., Chair

Robert Donmoyer, Ph.D., Member

Helen Eckmann, Ed.D., Member 
(C) Copyright by Kimberly S. Hogelucht 2011

All Rights Reserved 


\begin{abstract}
A growing body of literature suggests that networking promotes not only learning about one's field of interest but also employment opportunities, without requiring a formal job search. Considering three-fourths of job openings are never advertised (KossFeder, 1999), it appears networking is a powerful strategy in successful job attainment.

This study focuses on a less-than-obvious networking strategy, the informational interview. An informational interview is an interview with a professional that is conducted by a student or job seeker with the intention of finding out more about the professional's occupation or career field. In this study, informational interviews were examined, not only as a way of gaining knowledge about organizational roles (their articulated purpose), but also as a potential source of employment or internship offer. Although the business community is somewhat familiar with the practice of informational interviewing, a thorough search of scholarly business journals and databases sheds very little empirical knowledge on the subject.

This qualitative study focuses on the successful experiences of eight college business students who were offered internships by a professional as a result of an informational interview. The outcomes were striking and provoked the following research questions: 1) According to students and professionals, what interactional and structural conditions in the informational interview context fostered an internship offer? 2) How did the characteristics of the informational interview context differ from the characteristics of a formal interview context?
\end{abstract}

This study suggests that informational interviews are much more than a networking tool. They provide a strategy to secure internships. By examining the interplay between the structure of the interview and the interactions that ensued, this 
study shows how conditions were created that led to a deep understanding between the professionals and students. This deep understanding contributed to a sense of comembership between participants and fostered the willingness on the part of the professional to extend an internship offer. This study shows that because informational interviews address many of the limitations of formal job interviews, they appear to provide a better way for professionals to know a job candidate and assess job "fit." 


\section{Table of Contents}

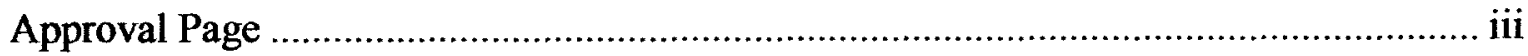

Institutional Review Board Clearance ..................................................................... iv

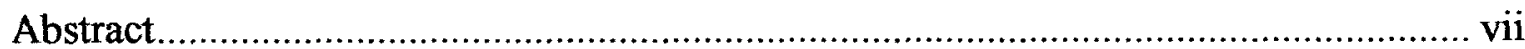

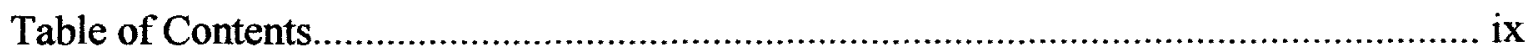

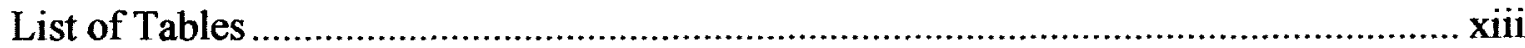

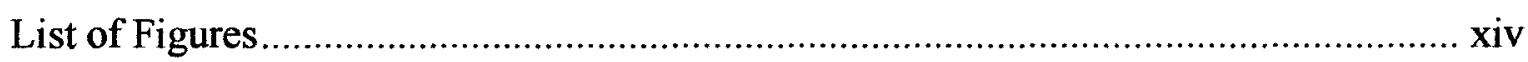

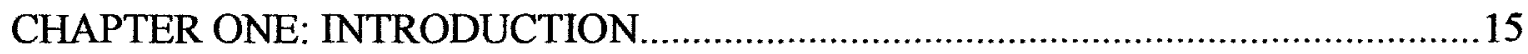

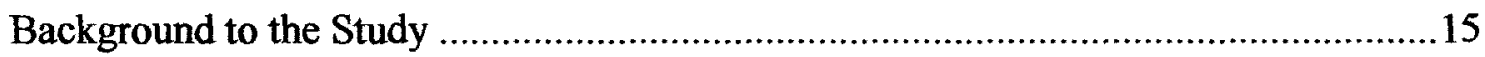

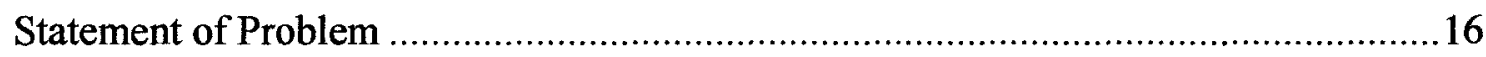

Purpose of Study and Research Questions ................................................................17

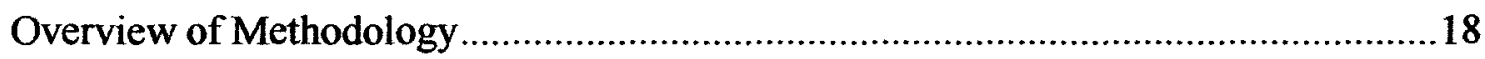

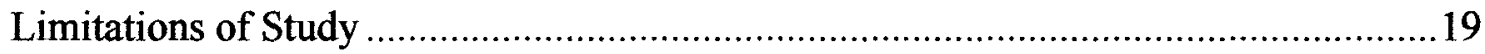

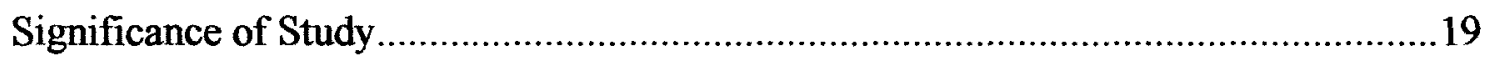

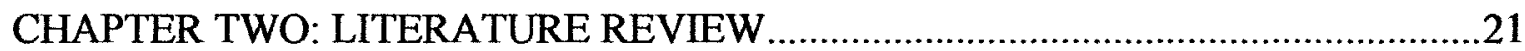

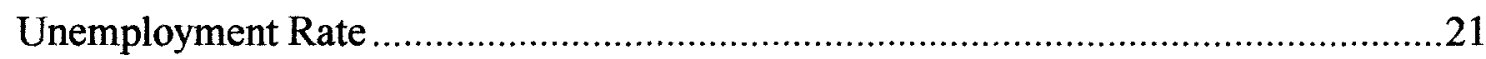

Value of Internships

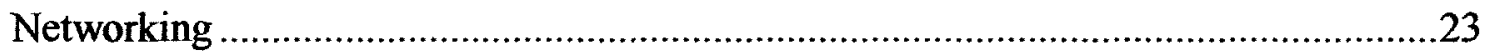

Costs of Job Search

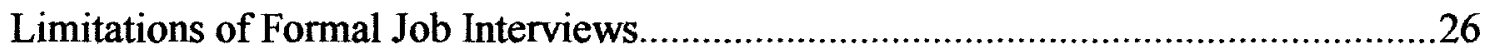

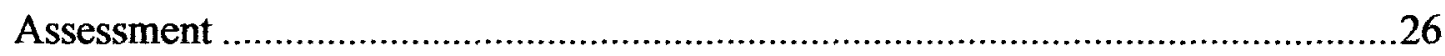

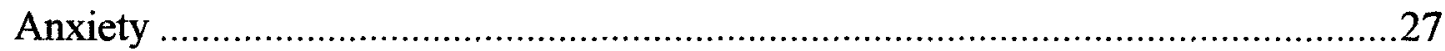

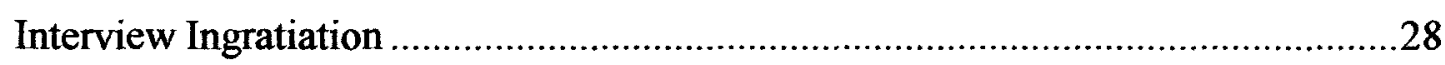

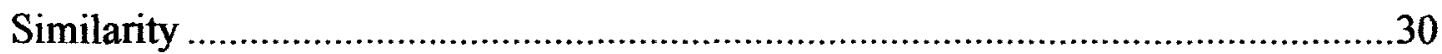




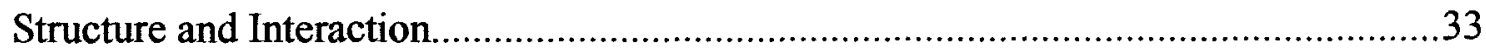

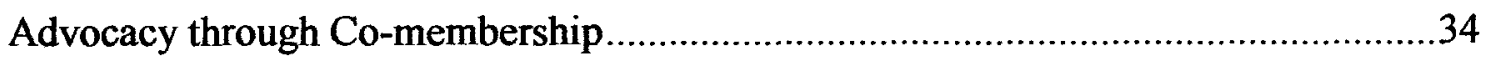

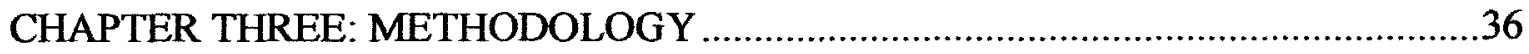

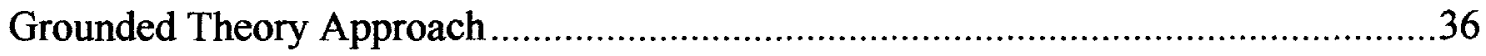

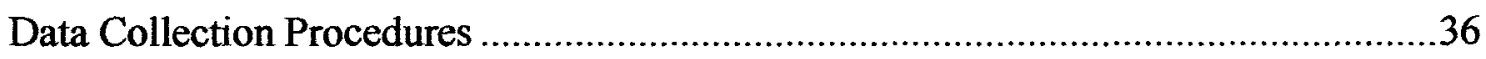

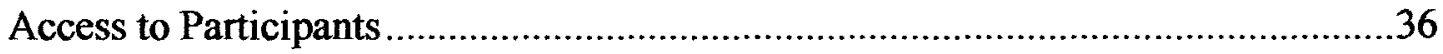

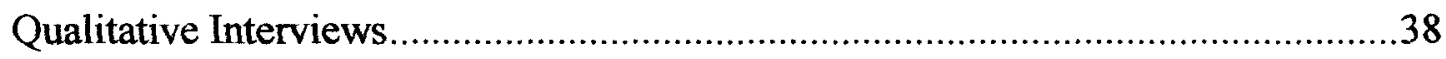

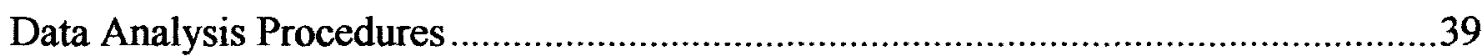

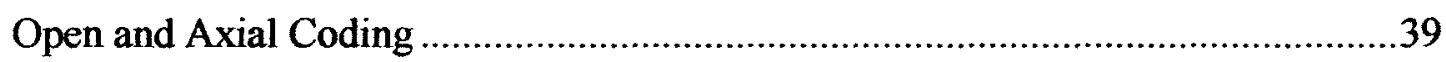

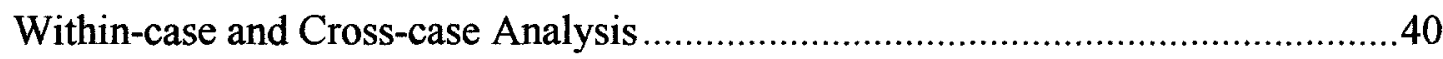

Application of Additional Theoretical Constructs...................................................40

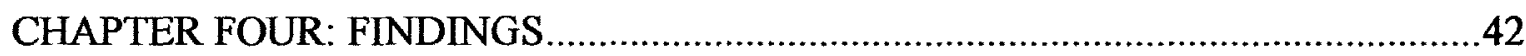

Section One: Background on Informational Interview Assignment............................43

Section Two: Outcome of the Informational Interview............................................4

Section Three: The Shaping and Re-shaping of Structure and Interaction ....................47

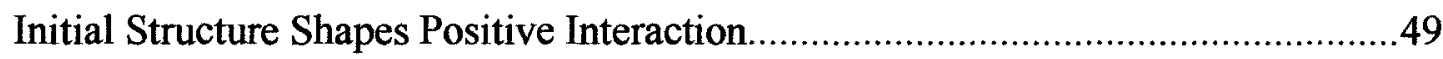

Comfort

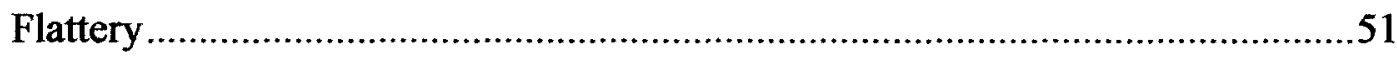

Positive Interaction Shapes Informal Structure ..................................................5

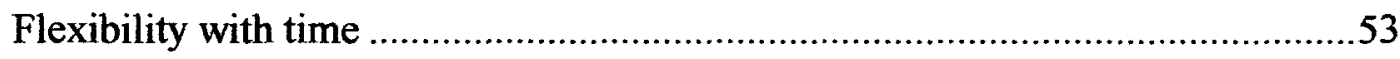

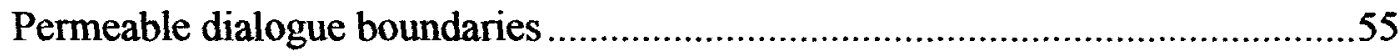

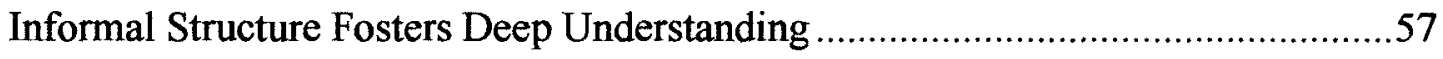

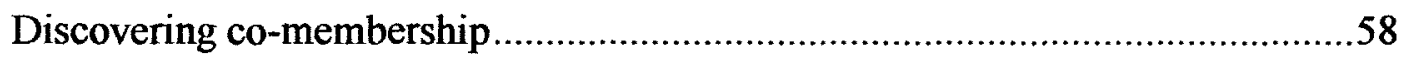

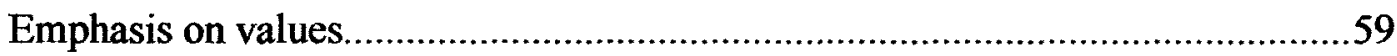


Passion 60

Professionalism

Integrity/work ethic 63

Deep Understanding Fosters Internship Offer 65

Informational interview "trumps" a formally structured interview. 65

Shift in structure 66

Interplay between structure and interaction. 68

CHAPTER FIVE: DISCUSSION .70

Informational Interviews as an Ideal Networking Tool 71

Initial Theory of Networking. 72

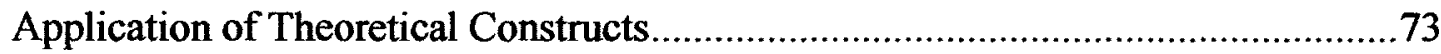

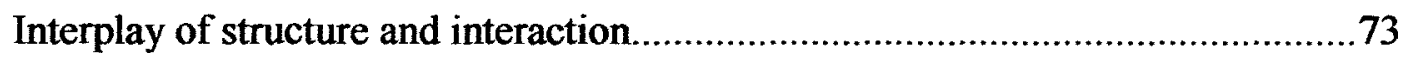

Advocacy through co-membership .................................................... 74

Informational Interview vs. Formal Employment Interview .................................76

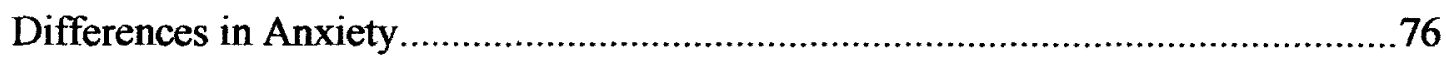

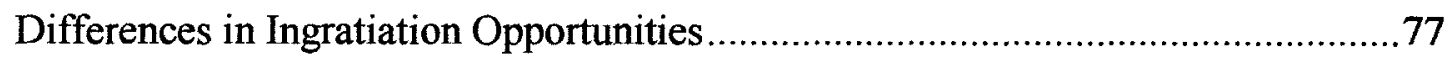

Differences in Level of Understanding...................................................... 78

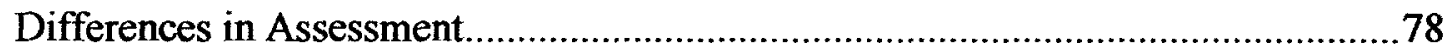

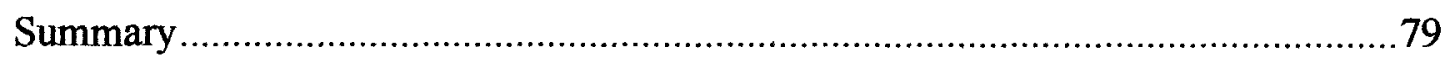

Implications for Employers, Job Seekers, and Educators....................................80

Practical Suggestions for Employers ........................................................8 81

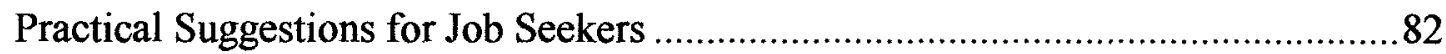

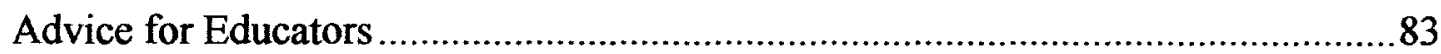

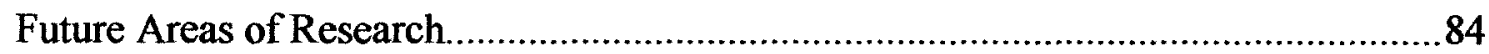




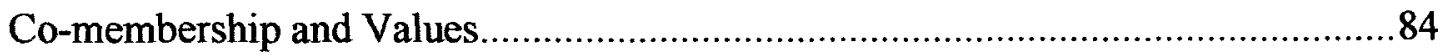

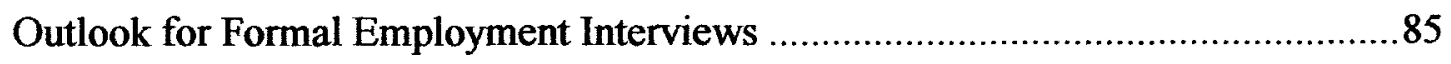

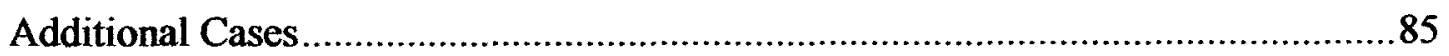

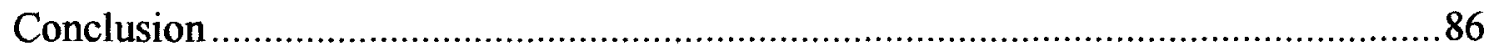

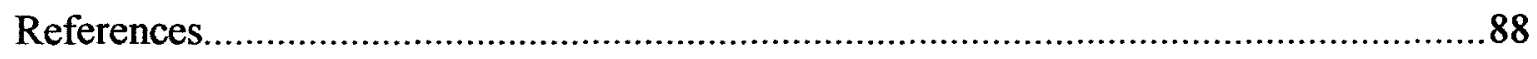

Appendix A

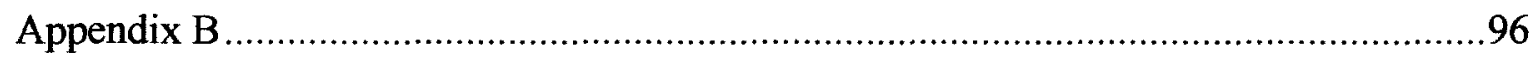

Appendix C

Appendix D

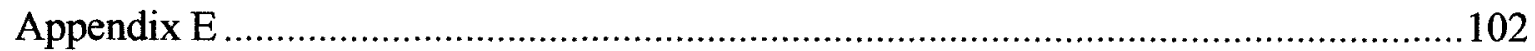

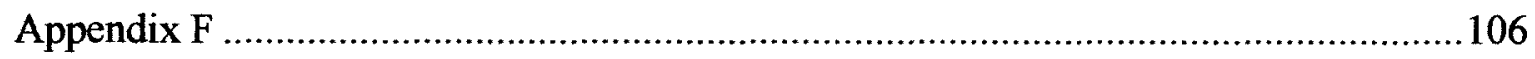




\section{List of Tables}

Table 1: Matrix of student analogies describing informational interview outcome.......46 


\section{List of Figures}

Figure 1: The shaping and re-shaping of structure and interaction............... 107 
TAPPING THE HIDDEN JOB MARKET THROUGH INFORMATIONAL INTERVIEWS:

\section{A QUALITATIVE EXAMINATION OF STUDENTS' AND PROFESSIONALS' PERSPECTIVES}

\section{Background to the Study}

The saying "It's not what you know but who you know" seems all too apt given that three-fourths of job opportunities are never advertised (Koss-Feder, 1999). In this turbulent economic climate, with a national unemployment rate of $9.7 \%$ and $12.6 \%$ in California alone, networking to pursue career goals seems even more relevant (Thompson, 2010; United States Department of Labor, 2010). Dr. Lynn Reaser, chief economist at Point Loma Nazarene University and former chief economist for Bank of America, recently spoke to a group of college students regarding the economy. Reaser said, "Expect the competition in the job market to be tough. You must do what you can to make yourself stand out" (Reaser, 2010). Research suggests that strategies such as networking may help a person differentiate him/herself from other job seekers.

Networking is a proactive attempt by individuals to develop and maintain personal and professional relationships with others for the purpose of mutual benefit in their work or careers (Forret \& Dougherty, 2001). A growing body of literature suggests that networking has a wide array of benefits. For example, it often promotes learning about one's field of interest and enlarging one's professional circle of contacts, and it enhances learning about employment opportunities without having to go through a formal job search and application process.

This study addresses one less-than-obvious networking strategy, informational interviews. An informational interview is an interview with a professional that is conducted by a student or job seeker with the intention of finding out more about the 
professional's occupation or career field. In this study, informational interviews were examined, not only as a way of gaining knowledge about organizational roles (their articulated purpose), but also as a potential source of employment or internship offers.

According to The Emerging Professional, an online career resource, "Internships can be a major pipeline for full-time hires - even in a down market: in 2008, $36 \%$ of all employment offers reported to the National Association of Colleges and Employers were made by companies to former interns" (Bryan, 2009). Additionally, the National Association of Colleges and Employers (NACE) reported that three-fourths of the companies they surveyed said they would prefer to hire a new college graduate who had relevant work experience such as an internship (Gerdes, 2009). Therefore, securing an internship through an informational interview may be even more significant than it appears on the surface, as there is a good chance it may lead to full-time employment with a company without a formal job search.

\section{Statement of Problem}

The majority of the literature on informational interviewing highlights the benefits of conducting informational interviews to find out information about a particular position/company or to bridge the gap between a student's academic life and career life (Crosby, 2002; Mulvaney, 2003). The informational interview, according to the literature, also allows a student to learn about the realities of his/her field of interest, a particular job or jobs within that field, and the workplace.

Although informational interviewing is not foreign to the business community as a means of learning about various occupations, a thorough search of scholarly business journals and databases does not produce any empirical studies on the subject. At present, the literature on employment interviews helps us understand a great deal about the formal 
job interview process and the behaviors that lead to job offers, but there is no systematically gathered evidence about informational interviews and the outcomes they produce. In fact, the only evidence I have been able to gather on the topic is informal, anecdotal evidence.

As a professor of business communication, I frequently ask students to conduct informational interviews, and I have been intrigued by the fact that some students return from conducting an informational interview with an unsolicited internship or, on some occasions, an unsolicited job offer. Even in the absence of formal research on this topic, the claim that conducting an informational interview allows a student to find out information about a company has considerable face validity; however, it is still not at all obvious what conditions are required for the professional to invite a student to continue his/her relationship with the organization after the informational interview is completed. There is a need, therefore, to systematically explore this topic.

\section{Purpose of Study and Research Questions}

Informational interviews are sometimes more than they appear to be. The purpose of this study is to examine the informational interview context to determine what conditions foster an internship lead or offer. The questions that will guide this study include:

1. What conditions in an informational interview foster an internship lead or offer?

a) According to students and professionals, what structural conditions exist in an informational interview context that may foster an internship offer?

b) According to students and professionals, what interactional conditions exist in an informational interview context that may foster an internship offer? 
2. According to students and professionals, how do the characteristics of the informational interview context differ from characteristics of the formal interview context?

\section{Overview of Methodology}

In this study, qualitative interviews were utilized to understand the phenomenon of students receiving unsolicited internship offers through their informational interviews. An interview guide (Patton, 2002) was used, but there was also freedom to probe further when the students or professionals said something particularly interesting. This seems to be an appropriate data collection method, because the topic of "informational interviews" is unexplored to date.

For this study, I interviewed eight students and eight professionals involved in informational interviews. As a professor of business communication, I had access to students and business professionals that was helpful in gathering data about informational interviews. The students I interviewed received internship offers with one of the eight professionals who will be part of this study. The students I interviewed were my former students, so I no longer had any direct authority over them.

This study used the grounded theory approach. The term grounded theory refers to both the process and product of a qualitative study. This process is, at least initially, largely an inductive one. That is, categories emerge from the data and are not preconceived prior to the collection and analysis of the data (Glesne, 2006; Patton, 2002). By looking at the emergence of an internship offer across cases, patterns and themes may be identified. Upon completion of the interviews, the interview tapes were transcribed and analyzed. Open coding was used to determine initial categories of information, followed by axial coding, which assembles data in new ways (Strauss \& Corbin, 1990). 


\section{Limitations of Study}

The main limitation to the study was the small number of cases analyzed and therefore the lack of generalizability in the traditional, scientific sense. The goal in grounded theory, however, is not to analyze data from a large number of cases in a single study; rather, the goal is to build general theory incrementally and inductively. This study aims to set the foundation for future research in this area, research that will eventually net an inductively generated theory about the role that informational interviews can play in moving up professionally.

A second limitation to this study was my role as an authority figure. Though I sought participation from former students, they may still have viewed me as an authority, causing them to feel more inclined to participate. I made certain to reassure them that participation was strictly voluntary.

Lastly, a limitation to this study was the scope of the context. This study addresses only one form of networking, the informational interview. As previously mentioned, this study is not intended to produce a general theory of networking that can be applied to all forms of networking. Rather, this study is a step in the generation of what may become a more general theory of networking in the future.

\section{Significance of Study}

In this turbulent economy, there is a need to identify effective ways to search for a job. This study reveals how one form of networking, the informational interview, may generate employment opportunities as well as identify conditions under which such opportunities arise. Through this understanding, ways to improve the formal job search process, more specifically, the formal job interview, may be inferred. Second, this study serves as a beginning step in the generation of a theory about unique forms of 
networking. It is a modest attempt in that it focuses on one form of networking, informational interviews, but it is indeed a first step. 


\section{CHAPTER TWO: LITERATURE REVIEW}

Because very little has been written about informational interviews, the literature review for this study focuses on what is known, especially in regard to the current unemployment rate and networking. Additionally, the literature review addresses some possible reasons job openings are filled through networking instead of the traditional means of filling a position, the formal job interview. Last, the literature review examines how the interplay between structure and interaction may influence an "interview" context, as well as how co-membership may contribute to positive evaluations in an interview setting. Therefore, the literature review focuses on 1) the current unemployment rate, 2) networking, 3) limitations of formal job interviews, 4) the interplay between structure and interaction on outcomes, and 5) the establishment of advocacy through co-membership and/or role-playing.

\section{Unemployment Rate}

With 15 million Americans jobless, the need for creative ways to secure employment is clear. In California alone, the unemployment rate hit a record high of $12.6 \%$, leaving 2.3 million Californians unemployed in 2010 - an increase in 362,000 jobless people in California from the year prior (Thompson, 2010; United States Department of Labor, 2010). Of the $9.7 \%$ unemployed, men were hit the hardest, with a $10 \%$ unemployment rate, compared to the $8 \%$ unemployment rate for women. According to Robert Reich, former U.S. Labor Secretary, "We're going to have high unemployment for the next few years. . . Even when jobs come back, they're not going to be very good jobs" (cited in Wiseman, 2010). Such a turbulent economy could make an employer more apt to hire interns as "inexpensive" help. 
With the third-highest jobless rate in the nation, California is searching for solutions. Arnold Schwarzenegger, then governor of California, suggested in 2010 that the state work on training employees and giving employers incentives to hire the unemployed. This appears easier said than done, as the Bureau of Labor Statistics expects consumer spending to grow only $2.5 \%$ per year from 2008 to 2018 , which is down an average annual growth rate of $3 \%$ in the past two decades (Wiseman, 2010).

\section{Value of Internships}

This economic outlook does not paint the most optimistic picture for current college students, who, upon graduation, will likely be faced with little opportunity to exercise their hard-earned academic skills and knowledge. For some college students, however, the swell in the unemployment rate provides an opportunity to stay in school and continue with graduate education. For students with fewer options or with a strong desire to enter the workforce, there is a quick realization of the need to "stand out" from the competition in the job market. As students look for ways to differentiate themselves to companies, many turn to internships (Bissonnette, 2010).

The value of an internship in securing full-time employment is supported by the National Association of Colleges and Employers, which indicated that more than $50 \%$ of all job offers from reporting companies were made to former interns within those companies (WSN, 2010), up from 36\% in 2009 (Bryan, 2009). According to a recent survey of companies looking to hire college graduates, $49 \%$ claim that they offer higher salaries to those students with internship experience (Normington, 2011). Furthermore, taking part in internships improves a student's employment prospects after college (WSN, 2010). The National Association of Colleges and Employers states that students without internship experience "have unrealistic views of work, lack maturity and work 
ethic, lack commitment to the organization, and possess less awareness of business etiquette" (as cited in Normington, 2011).

With this recent realization of the value of internships, the process of securing an internship has become very competitive--so competitive that some students are even turning to fee-based internship programs (Normington, 2011). The Washington News Square reported that "the dismal economic climate necessitates providing every possible resource to students bound for the job market - helping students find internships is, now more than ever, a huge part of that" (WSN, Sept. 2010). With this in mind, it appears that securing an internship plays a vital role in securing employment. Though securing internships has become competitive, this study suggests that discovering such internship opportunities may most likely result from some form of networking.

\section{Networking}

A growing body of literature suggests the value of networking to learn more about one's field of interest, to expand one's contacts, and to learn about employment opportunities without going through the formal job search process. Networking involves people making an effort to meet other people for the purposes of cultivating mutually beneficial, give-and-take, win-win relationships (Burg, 1998; Forret \& Dougherty, 2001). According to Owens and Young (2008), when meeting someone, one's emphasis should be on getting to know the other person rather than on how one can obtain employment. Networking is all about listening and being "you" focused rather than "I" focused (Burg, 1998).

Some research suggests that being "you" focused may come more naturally for women than men (Helgesen, 1995). With men taking the hardest hit in unemployment, learning about and utilizing networking strategies may perhaps help them the most. 
However, there are mixed conclusions on this subject. According to Sally Helgesen, author of The Web of Inclusion: Architecture for Building Great Organizations (2005) and the Female Advantage: Women's Ways of Leadership (1995), most women have been raised from birth to be empathetic and intuitive, and to communicate their thoughts and feelings. Helgesen asserts that these aspects of women's socialization result in their ability to build networks or "webs" of contacts more naturally than men. Conversely, a study on networking by Forret and Dougherty (2004) found that women use fewer networking strategies than men. The authors suggest that networking may be a promising career strategy for women. They suggest future research address why women build less effective networks. Putting gender aside, the fact still remains that the unemployment rate is high and affects everyone in some way.

Additionally, de Janasz and Forret (2008) suggest that our "boundaryless" work environments involve frequent job changes within and across organizations (Arthur \& Rousseau, 1996; Sullivan, 1999) as well as the shift in responsibility for one's job from the company to the individual (Hall, 1996; 2002). For these reasons, researchers suggest the growing need for developing relationships through networking (de Janasz, Sullivan, \& Whiting, 2003; Higgins, 2000; Higgins \& Kram 2001).

According to de Janasz and Forret (2008), developing human capital is the focus of the educational system. Human capital constitutes the skills and abilities that make one desirable to employers. The research suggests, however, that in addition to enhancing human capital, many college students need to work on developing their "social capital" (Burt, 2004; de Janasz \& Forret, 2008). "Social capital" is defined as the resources or opportunities available to an individual as a result of his/her relationships (Baker, 2000) and networking is viewed as one form of human capital that may serve to enhance one's 
social capital - such as job offers and promotions. Additionally, professionals with social capital are aware of and exercise control over opportunities. They see how the needs of one person or group could benefit another person or group. They also tend to offer inexpensive and timely coordination and organization of information, as opposed to the bureaucratic alternative (Burt, 1998, 1992). Furthermore, professionals who have contacts within and across different groups are more familiar with alternative ways of thinking and behaving (Burt, 2004). With this in mind, a professional may leverage his/her social capital in order to hire someone without following the formal hiring process of the organization.

As previously stated, three-fourths of job openings are never advertised. Why employers are bypassing the formal interview process and filling positions through other avenues calls for a critical look at the formal job search process.

\section{Costs of Job Search}

At some time in their life, most people will take part in the job search process either as a potential employee or as the employer, both seeking a "right fit." Warren Bennis, professor of business at University of Southern California, claims the search for top talent is "the most significant problem facing all organizations" (Bennis, 2000). It is also well-known that this search for talent does not come without a cost.

Job searching requires a great deal of human and fiscal resources. Research shows that the average amount of time spent recruiting, screening, and interviewing job candidates for most organizations is approximately eight hours per position, including an average of six applicants interviewed for each position (Barron, Bishop, \& Dunkelberg, 1985). Research also reveals the average cost to hire for one open position is $\$ 5,000$ (IHRIM, 2010), and hiring the wrong person for a position can cost an organization as 
much as three times the position's base salary (Remillard, 2009). The time and cost of hiring are so significant to organizations that some career search websites offer online cost-per-hire calculators for employers to predict the cost associated with hiring a new employee (HR World, 2011). Not only are costs an issue with the formal job search process, but the actual practice of formal interviewing also appears to have limitations.

\section{Limitations of Formal Job Interviews}

\section{Assessment}

The traditional method for a formal employment interview involves an employer asking an applicant questions to assess the skills and overall "fit" of the applicant for the position. Because formal employment interviews last a fairly short time, the interviewer (the employer) tends to get right down to business. The "business" in this case is asking the applicant questions pertaining to his/her strengths, skills, weaknesses, and so on. This is done to assess whether the interviewee is a good candidate for the job. In the $1990 \mathrm{~s}$, a body of literature suggested that formal interviewing may not be the best way to get to know a candidate:

While naive interviewers may fail to recognize the theatrical quality of applicant behavior, trained interviewers may focus only on this quality and seek to penetrate interviewee performance. Paradoxically, however, [interviewers'] efforts to outsmart applicants invited applicant performances that are hard to interpret. These efforts also create a communication setting unlike that in the workplace, and they deprive applicants of information they need to make wise employment decisions. (Kirkwood \& Ralston, 1999, p. 56)

Kirkwood and Ralston suggest that applicants work on practicing conscious transparency and employers work on making the formal interview a communication context similar to the work context. They suggest that employers avoid following the advice of experts on interviewing, otherwise employers will find themselves cast in the role of Sherlock Homes, trying to deduce from interview questions the real truth about the applicant. 
Similarly, Hunter and Hunter (1984) questioned the validity of interviews and found that interviews are not a valid means of assessing the work potential of job candidates. The authors concluded that the validity for the formal employment interview is only 0.11 , leading to their conclusion that the formal interview is not a strong predictor supervisor rating of performance. They claimed that the validity of the interview greatly varies from one setting to the next, and in about one-sixth of settings, the validity reaches a reasonable level of .20 or better. They claim that the validity of the interview varies according to some subtle organizational features not yet known. With this in mind, they recommended further research to detect these unknown features.

\section{Anxiety}

For an applicant who is searching for the "right" answers and wants to appear to be the best "fit," it is not surprising that anxiety enters into the formal interview as another limitation. Yuen (1998) contends that feelings of anxiety are common in the fastpaced and stressful work environment of our day: "A key source of this anxiety is the employment interview, which is the most common selection device used by organizations" (Posthuma, Morgeson, \& Campion, 2002). The nature of a formal interview involves the employer controlling the questions asked while at the same time evaluating the applicant. With so little control over the questions asked and the threat of giving the "wrong" answer, it is not surprising that the formal interview has been named one of the top fears of college students. Research suggests that high levels of anxiety may result in low interview evaluations, in spite of the fact that the applicant may demonstrate superior on-the-job performance if hired (McCarthy \& Goffin, 2004). Furthermore, Jones and Pinkey (1989) claim that "employment interviews are typically not under the 
applicant's control, and this lack of control may lead to heightened feelings of anxiety" (p. 608).

Performance anxiety, as defined by Hopko, Hunt, and Armento (2005), involves responding anxiously to the immediate threat or anticipation of a performance and the negative evaluation that may be associated with it. A formal interview could be viewed as one such "performance" that would produce some threat or anticipation of negative evaluation, for a job is at stake. The authors view performance anxiety as an umbrella term encompassing other anxiety conditions, including social phobias, test and math anxiety, and music performance anxiety.

Although researchers have identified the need for programs aimed at reducing anxiety in interview candidates (McCarthy \& Goffin, 2004), evidence from Young, Behnke, and Mann (2004) indicates that eliminating anxiety may be difficult to accomplish. Their research found that anxiety is sustained during formal interviews due to constant interaction and evaluation. Unlike public speaking, in which anxiety usually drops after the speaker's introduction, the pressure to perform in a formal interview is constant and fear of failure persists.

\section{Interview Ingratiation}

In spite of the limitations of assessment and anxiety, one way job applicants put themselves at an advantage in formal interviews is by using impression management. Research has shown, however, that formal interviews provide few opportunities to use impression management. Impression management is defined as a "conscious or unconscious attempt to control the images that are projected in . . social interactions" (Schlenker, 1980, p. 6). Tsai, Chen, and Chiu (2005) found that highly structured 
interviews allowed less freedom for applicants to effectively exercise impression management techniques, such as ingratiation.

When studied, impression management is commonly broken into two categories: self-directed behaviors and other-directed behaviors. Self-directed behaviors such as selfpromotion are used to make it appear that one has relevant skills and possesses positive qualities. Other-directed behaviors are similar to ingratiation in that they are used to make others feel good about themselves or to show that one holds similar beliefs, feelings, and values (Wayne \& Kacmar, 1991). Ingratiation is defined as "the act of gaining acceptance or affection for yourself by persuasive and subtle blandishments [characterized by flattery or compliment]" (Ingratiation, WordWeb, 2009). McFarland, Ryan, and Kriska (2002) explain ingratiation as getting another person in "a good mood or to think favorably of you by complimenting them-before asking the other person to do something" (p. 386). Therefore, ingratiation has been identified as a key strategy employed by interviewees to gain employment from a formal interview.

Furthermore, Higgins and Judge (2004) examined the impact of influence tactics and fit perceptions on the interview process. They found that ingratiation is positively related to recruiter hiring recommendations. They argued that the employment interview is prone to influence tactics that can be used to manage perceptions and that ingratiation is one way to influence in the interview. They contend that ingratiation, such as opinion conformity, appears to exert influence on outcomes primarily through its effect on the perceptions of fit (fit between applicant and organization or applicant and job). Similarly, additional studies (Ellis, West, Ryan, \& DeShon, 2002; McFarland, Ryan, \& Kriska, 2002) found that self-promotion and ingratiation tactics are positively related to interviewer evaluations. 
Additionally, Gilmore and Ferris (1989) found that applicants who exhibit high impression management techniques are perceived as having effective communication skills, being more complimentary, and as highlighting their positive characteristics. The researchers claim that their study provides an initial step in understanding the role impression management techniques play in the formal interview process. They stress the importance of finding out more about the conditions under which impression management plays a role in the formal employment interview process.

\section{Similarity}

Finding similarity with another, such as agreeing with another's opinion, is yet another way that applicants may utilize impression management techniques such as ingratiation (Higgins \& Judge, 2000), but the extent to which similarity is assessed beyond surface level similarities, such as demographics, may be limited in a formal interview due to the nature of the interaction and the issue of time (Harrison, Price, \& Bell, 1998). Because formal employment interviews last a fairly short time, the interviewer (the employer) tends to get right down to business. The "business" in this case is asking the applicant questions pertaining to his/her strengths, skills, weaknesses, and so on. This is done to assess whether or not the interviewee is a good candidate for the job. This quick questioning usually leads to hiring decisions based more often on surface-level conditions such as demographics (age, sex, race/ethnicity) rather than on more in-depth information such as beliefs or values: "[D]emographic factors are often a poor surrogate for the deeper-level information people need to make accurate judgments about similarity of attributes among group members" (Harrison, Price, \& Bell, p. 104). The researchers contend that it is only through extended individualized interaction and information gathering that deep-level similarities can surface. Therefore, a formal 
interview, which is typically time-bound, structured in a "question-answer" format, and led by the employer, may not be the best way to discover these deeper-level similarities and thus, may foster inaccurate judgments.

Earlier work on the connection between similarity and evaluation suggests Harrison, Price, and Bell were not the first to break ground in this area. As early as 1959, Triandis examined the effect of similarity on the superior-subordinate relationship. He asked the superiors and corresponding subordinates participating in his study to respond to questions about jobs and people. He found that the more similar the responses of subordinates and superiors, the better the subordinates liked their superiors and the better they worked together.

In 1961, Newcomb assessed "attraction" by looking at similarities before and after two people meet. He measured attraction by means of a rank ordering of group members and by a 100-point rating scale concerning "favorableness of feeling toward each of the group members." The results reveal that agreement on attitudinal topics and values prior to acquainting two people was associated with attraction after acquaintance. Similarly, in 1962, Burn and Wong found a positive relationship between attitudinal similarity and favorable evaluations. They found that people initially perceived greater attitudinal dissimilarity between themselves and another race, but when more details were provided about the strangers' attitudes, the perceptions of dissimilarity decreased and interpersonal attraction increased. Likewise, researchers have found that the degree of similarity influenced negative or positive evaluations. Byrne and Rhamey (1965) revealed highly significant effects for both attitude similarity and personal evaluations. Byrne, Young, and Griffitt (1966) found that both similar attitude statements and neutral 
statements acted as positive reinforcements while dissimilar statements acted as negative reinforcement.

In 1967, Byrne and Clore found that the extent of arousal is crucial to determining a response to similar and dissimilar values. If something is important, a person puts more weight or emotional value on it: "Major aspects of the world, such as attitudes, opinions, beliefs and values are such items that lead to strong feelings" (Byrne \& Clore, 1967, p. 34). Thus, it is not surprising that agreement on values or opinions would lead to favorable evaluations of another person.

Byrne's similarity-attraction theory was introduced in 1969. This theory provides a framework for understanding the positive relationship between ingratiation and hiring recommendations. The common belief that "an individual's stated attitudes influence the way in which others evaluate him or her" is observable and comes as no surprise to many people. Byrne (1969) sought to quantify this common belief as it was observed among many spouses and friends. Byrne claimed, "The general relationship between reinforcing stimuli (of whatever kind) and evaluating responses (of whatever kind) involves a broad sphere of behavior and a host of research possibilities" $(1969$, p. 85). His theory of similarity-attraction reveals that an attraction to others similar to oneself is largely based on attitudinal traits or values, and that this attraction does go beyond spouses and friends to permeate other contexts as well.

Later, Rand and Wexley (1975) found that biographical similarity between interviewer and applicant lead to higher ratings of an applicant's suitability for the job. Similarly, Schneider's (1987) attraction-selection-attrition framework suggests that most recruiters will look favorably upon applicants who are similar to themselves and other members of the organization. Conversely, recent research by Goldberg (2005) supports 
sex-dissimilarity in hiring. For instance, Goldberg found that male recruiters favored female applicants, but there was no applicant sex effect for female recruiters. He claims recruiters may be looking for the "ideal" applicant rather than the "similar to me" applicant. Goldberg suggests that an important contribution to the literature would be assessing the extent to which recruiters may be looking for employees with certain demographics and how this bias influences the selection process in interviews.

Because the job search process appears to be problematic for a number of reasons, including cost/time involved and the limitations of formal interviews, could an informational interview be a better device for both the job candidate and employer to get to know each other and to more accurately assess job "fit"? Research reveals that an examination of structure and interaction, as well as co-membership, may help in understanding these issues.

\section{Structure and Interaction}

While the support for looking at both structure and interaction in shaping meaning and outcomes has been recognized since the early 1960 s, many early researchers were faulted for not giving much attention to the role "interaction" played (Berger \& Luckman, 1966; Garfinkel, 1967; Blumer, 1968). More recently, the role both structure and interaction play in shaping meaning and outcomes has been stressed: "[T] connect the macro [structure] to the micro [interaction] is worth making as the power of explanatory theory on either level will be enhanced if we can show their mutual penetration in a fairly precise way" (Collins, 1987, p. 195). For instance, one might consider if the structure of the informational interview influences the interaction that ensues. One might also consider if a company's structure (including size and formal 
processes) influences the extent of a professional's freedom in offering internships without going through the formal job search process.

Early research projects in the area of structure and interaction consisted of violating social norms or rules (structural conditions) in order to expose them (Garfinkel, 1967). Garfinkel wanted to show society that rules are shaped and supported by interpersonal interactions. It is when society violates those rules that the prevalence of them is truly seen. I believe the present study accomplishes this "exposure" from the outset, for the informational interview violates the social norms or rules of engagement for an "interview." The student is interviewing the professional and there is no job at stake; it is definitely not a typical interview. By shifting the traditional structure of an interview, how is the interaction influenced? How is the interaction similar to or different from a formal job interview? By changing the rules of a traditional job search device, the formal interview, the present study allowed for an understanding of this job search device at work under a different structure and set of rules. Therefore, the impact the structural and interactional conditions have on shaping and re-shaping each other is a vital part of this study.

\section{Advocacy through Co-membership}

Although the interplay between structure and interaction is examined in this study, another theory related to interaction, co-membership, may shed additional light on why the professionals served as advocates for the students.

Research by Erickson and Schultz (1982) revealed that when counselors met with students, they were more likely to help students whom they had more in common with. The researchers used the term "co-membership" to describe the discovery of shared attributes or status or common interests. 
Additionally, Erickson and Schultz (1982) found that small talk between counselors and students led to the discovery of co-membership. Likewise, Collins (1987) found that conversations were chains of interactions resulting in the inclusion or exclusion of individuals from group membership. Furthermore, Erickson and Schultz (1982) recommended more counselors engage in small talk with students and, instead of viewing it as "wasted time," view it as a chance to discover "co-membership," or what the counselor and students have in common. They found that discovering "comembership" caused the counselor to serve as an advocate for the student. By looking at the nature of the interaction between the student and the professional in an informational interview, we are able to see if co-membership is established and if, indeed, this comembership leads to advocacy of the student in terms of an internship offer.

The job search process appears to be problematic for a number of reasons: cost/time involved and the limitations of formal interviews. In light of these issues, the question arises as to whether informational interviews hold some promise for securing employment that is a "win-win" situation for both job seekers and employers. By examining the interplay between structure and interaction in the informational interview context, as well as looking at co-membership, the present study intends to shed light on these issues. 


\section{CHAPTER THREE: METHODOLOGY}

\section{Grounded Theory Approach}

This study made use of the grounded theory approach. The term grounded theory refers to both the process and product of a qualitative study. This process is, at least initially, largely an inductive one. The product produced by the process is theory that is "grounded," generated directly from the data (Patton, 2002). That is, categories emerge from the data inductively and are not preconceived prior to data collection or analysis. By looking at the phenomenon of receiving an internship offer through an informational interview across multiple cases, patterns and themes may be identified.

Charmaz (as cited in Merriam and Associates, 2002) asserts that grounded theory produces substantive theory regarding some part of life, including various forms of professional practice. The present study will investigate how a particular professional practice, the informational interview, may generate an internship offer or lead. By tapping students' and business professionals' perspectives, this study will be an initial step in constructing a grounded theory about networking practices students use to enter the labor force.

\section{Data Collection Procedures}

\section{Access to Participants}

Patton (2002) states, "Grounded theory depends on methods that take the researcher into and close to the real world so that the results and findings are grounded in the empirical world" (p. 125). As a professor of business communication at a private university in Southern California, I have access to former students and business professionals who took part in informational interviews. This accessibility was helpful in gathering data about informational interviews. 
In this study, I interviewed eight professionals and eight students involved in informational interviews. The students received internship offers through their informational interviews. They were my former students, so I no longer had any direct authority over them. The professionals I interviewed were the corresponding professionals who offered the students internships during the informational interview the students conducted with them.

This selection process began with emails to my former students to find out who was offered an internship through their informational interviews. In the email, I explained the focus of my study: to explore the informational interview context, to find out how it differs from a formal employment interview, and to explore reasons why the student feels he/she was offered an internship. I then extended an invitation for them to be interviewed by me, explaining that participation was voluntary and that pseudonyms would be used (See Appendix A for a copy of the email). After each student who agreed to be interviewed emailed me, I clarified with each student that they 1) did not know the professional before the informational interview, and 2) that the professional clearly initiated the internship offer, not the student. I then asked those who met the criteria for permission to interview the corresponding professional who offered the internship.

After obtaining permission, I then emailed the corresponding professionals. In the email, I explained the purpose of my study - to obtain a professional's perspective on informational interviews. I also explained that participation was voluntary and that pseudonyms would be used (See Appendix B for a copy of the email). The first eight pairs of students and professionals who agree to be interviewed became part of the study. 


\section{Qualitative Interviews}

Qualitative interviews were conducted with both the students and business professionals. An interview guide was utilized. An interview guide "provides topics or subject areas within which the interviewer is free to explore, probe, and ask questions that will elucidate and illuminate that particular subject" (Patton, p. 343). The topics and subject areas were stated in the form of questions for the interviewee. Using an interview guide rather than a completely pre-set interview schedule permits some degree of focus and standardization across interviews but also provides for the flexibility to probe deeper when an interviewee's response needs further clarification or is especially provocative.

Questions for the students centered on their informational interview experiences, the differences between an informational interview and a formal employment interview, and the conditions they feel helped them secure internship offers through their informational interviews (See Appendix C for student interview guide). Interviews with professionals focused on their informational interview experience, the differences between an informational interview and a formal employment interview, and conditions under which they offered the students internships (see Appendix D for professional interview guide). Interviews lasted approximately 30 minutes. I asked for permission from the participants to record the interviews. When possible, I recorded the interviews, thereby allowing me to capture the exact words of the participants and also allowing me to actively engage in listening and probing instead of being preoccupied with taking notes. 


\section{Data Analysis Procedures}

Upon completion of the interviews, the interview tapes were manually transcribed by the researcher and analyzed. Due to such a small number of cases involved in the study, there was no need to use computer software for the purposes of analyzing data.

\section{Open and Axial Coding}

Patton (2002) asserts that by immersing oneself in the specifics of the data, one can discover important patterns, themes, and interrelationships. Categories or themes and the relationships between them are derived inductively from the data through a progressive process of sorting and defining (Glesne, 2006). Open coding was used to determine initial categories of information. Open coding "fractures the data and allows one to identify some categories, their properties, and dimensional locations" (Strauss \& Corbin, 1990, p. 97). This was followed by axial coding, which "puts those data back together in new ways by making connections between category and its sub-categories" (p. 97).

Those conditions critical to understanding how and why a student receives an internship offer was the focus. This analysis was not guided by rules, but instead by analytical analysis and creative synthesis, which involves uncovering and examining the details of the data in order to discover patterns, themes, and new connections. (Patton, 2002). Initially, I examined themes related to "structural and interactional conditions" that foster an internship offer from both students' and professionals' perspectives. For example, structural conditions could be viewed as conditions that deal with the format and objective of the context, company policy for internships, and so on. Interactional conditions could be understood as conditions that address the nature of the interaction, such as the topic of the conversation, or nonverbal and verbal communication. I expected 
that other conditions, beyond structural and interactional conditions, may surface as the interviews are analyzed.

\section{Within-case and Cross-case Analysis}

In this study, I defined a "case" as the student and corresponding professional involved in an informational interview. This study provided for a within-case analysis by pairing the student with the professional he/she interviewed and a cross-case analysis by comparing the views of students with other students and professionals with other professionals. Themes as well as discrepancies were also noted. Glaser and Strauss (as cited in Patton, 2002) stated:

[C]ross-case analysis can begin in search of patterns and themes that can cut across individual experiences. The initial focus [of an inductive analysis] is on full understanding of individual cases before those unique cases are combined or aggregated thematically. This helps ensure that emergent categories and discovered patterns are grounded in specific cases and their contexts. (p. 57)

In other words, the present study allows for a comparison of results on several levels.

This allows me to examine the richness involved in the process of informational interviewing and helps me to understand the various conditions involved in the generation of an internship offer.

\section{Application of Additional Theoretical Constructs}

After the gathering of data, several theoretical frameworks were applied to the data to help the data make greater sense. The two frameworks that were applied to the data include: 1) the interplay between structure and interaction and 2) co-membership.

Although the importance of looking at both structure and interaction in shaping meaning and outcomes has been recognized, many early researchers were faulted for not giving much attention to the role "interaction" played (Berger \& Luckman, 1966; 
Garfinkel, 1967; Blumer, 1968). More recently, Collins (1987) has encouraged more research on the role both structure and interaction play in shaping meaning and outcomes.

Additionally, the theoretical construct of "co-membership" described in previous research by Erickson and Schultz (1982) was applied to help make greater sense of the data. As previously mentioned in Chapter One, co-membership involves discovering what each of the participants in the interview had in common. In their research, Erickson and Schultz discovered that when the counselor established that there was something that he or she shared with a student-when a high co-membership existed- the counselor became an advocate for the student. This construct was applied to the findings to help make greater sense of the professionals' advocacy of the students.

This qualitative study attempts to generate a theory of networking by examining informational interviews as a means to employment. The hope is that through the voices of students and professionals, the beginnings of a theory of networking may emerge. Ultimately, this study produces an initial theory and model to depict the results visually. Though the majority of job openings are currently being filled through various forms of networking, it is a subject that has yet to be studied from a scholarly stance and is certainly due for a closer look. 


\section{CHAPTER FOUR: FINDINGS}

While informational interviews are intended to shed light on a field of interest, this study reveals how informational interviews provide structures that allow for specific kinds of interactions that foster an internship offer. Working inductively under a grounded theory approach, the data in this study were collected through interviews with eight students and the corresponding eight professionals who participated in informational interviews that produced internship offers. In this chapter, I examine the reflections of those students and professionals involved in informational interviews that produced internship offers.

The first section of this chapter is intended to provide background on the informational interview assignment and the surprising outcomes it —at times--produced and that prompted this study. The second and third sections of this chapter focus on the data collected in this study and highlight categories that were formed after the data were collected and analyzed, leading to an initial theory of networking. Several theoretical constructs were incorporated into the findings only after an initial analysis of the data, when it was realized they fit comfortably onto the data and helped the data make greater sense.

The findings are organized as follows: 1) a description of the informational interview assignment and purpose, 2) the outcome of the informational interview as described by students, and 3) how structure and interaction shaped and were shaped by each other in a way that fostered internship offers during the informational interview, according to students and professionals. 


\section{Section One: Background on Informational Interview Assignment}

This section provides the background leading up to this study. It describes how the informational interview assignment was explained to the students and the surprising outcomes some informational interviews produced, leading to the need for the present study.

The pedagogical purpose of this assignment was to help students fine-tune their career goals. It was designed to expose students to a field/career of interest, to unveil the pros and cons of a field/career, and, ultimately, to help them decide if they were on the right career path or if they needed to change their course of action. I encouraged my students to schedule interviews with three professionals in what they would consider to be "dream jobs," and in preferably high-status positions, as this was a wonderful opportunity to meet with professionals who likely would have many years of experience and who could share many valuable lessons with them.

In locating the three professionals to interview, I advised my students to talk to their parents' friends and their friends' parents. They could also check the yellow pages and do research online regarding companies or positions in their line of interest. I even recommended they actually go to businesses they were interested in and inquire about the opportunity to conduct an informational interview.

To make the request for an informational interview, I instructed my students to call and email professionals and explain that this was an assignment for their Business Communication course. I also instructed them to ask for twenty minutes of the professionals' time. The time frame seemed appropriate given that professionals are busy people and that asking for more than twenty minutes might cause them to be more likely to say "no." I presented examples of questions to ask, such as, "What do you enjoy about 
your job?" However, I informed my students that it was really up to them to determine what they wanted to ask (See Appendix E for assignment). I gave the students enrolled in Business Communication one month to complete the assignment.

After the informational interviews were assigned, the students secured three informational interviews. Students complied with all directions. Based on an informal hand count taken in class, however, several students (approximately 15\%, 10 out of 60 students) returned acquiring more than just knowledge about a career of interest; they returned with an internship offer. This deviation from the articulated purpose of the assignment suddenly made the informational interview a phenomenon of interest and, more importantly, a phenomenon that justified careful study.

The surprising outcome of the informational interviews, led me, as an instructor, to ask, "Why did some students get more than the information they sought? Why were they offered an opportunity to become connected with the organization through an internship?" These questions led me to conduct the present study. The next section highlights how eight students, who were offered internships, reflected back on and described their informational interview outcome.

\section{Section Two: Outcome of the Informational Interview}

Six of the eight students commented that it was the most valuable assignment they had completed in their college career. Due to the fact all eight students received internship offers through their informational interviews, it was not surprising students felt this way. The fact that eight students received internship offers, when this was not the intended purpose of the assignment, made this a particularly interesting issue to investigate. It was as if the informational interview served as a way for students to secure 
an internship and perhaps set themselves on a path to full-time employment without going through a formal job search.

When asked what they would compare their informational interview experience to in terms of processes and outcomes, six of the eight students shared analogies. The two students who did not offer a comparison said they could not think of one. The analogies included: getting a free ticket, a free pass, stopping time, a bright arrow, Pandora's box, and reverse psychology (See Table 1 below). 
Table 1

Matrix of student analogies describing informational interview outcome

\begin{tabular}{|c|c|}
\hline Analogy & Student Response Context \\
\hline $\begin{array}{c}\text { "Getting a Free } \\
\text { Ticket" }\end{array}$ & $\begin{array}{l}\text { "The informational interview is like getting a free ticket that gets you } \\
\text { into the drawing, and the internship is the reward. The ticket was given } \\
\text { to you, you just have to reach out and take it. ... Just like with an } \\
\text { informational interview, the opportunity is there, you just have to reach } \\
\text { out and take it. But the big difference between informational interviews } \\
\text { and a drawing is that with an informational interview, you have a high } \\
\text { chance of winning... which is getting an internship." }\end{array}$ \\
\hline "A Free Pass" & $\begin{array}{l}\text { "It's like a free pass. I think that you go in there not expecting anything, } \\
\text { and you leave with a job. That doesn't happen very often, especially with } \\
\text { a job. I mean you don't even have to put in the work to actually be in the } \\
\text { hot seat and apply; you can just talk to someone casually. You just go in } \\
\text { there and do an informational interview, and you get offered a job. I } \\
\text { mean, that's definitely a free pass." }\end{array}$ \\
\hline $\begin{array}{l}\text { "Stopping } \\
\text { Time" }\end{array}$ & $\begin{array}{l}\text { "This is kind of random, but I feel that in life you are always trying to } \\
\text { get to a certain point, and it would be so nice to just stop time and be } \\
\text { ahead of the game for a second. And I feel like that is what an } \\
\text { informational interview allows you to do. I mean, if you go through the } \\
\text { normal process of a formal job interview, you're always being } \\
\text { questioned, always being on the edge, like am I in or out, in or out, like } \\
\text { do I get the job, do I get the internship, did I get into the school that I } \\
\text { want to be in, and it would be so nice ... like if I was applying for a job, } \\
\text { it would be so nice to say to the interviewers or recruiters what exactly } \\
\text { are you looking for, so that I could know if I could ever be that or what I } \\
\text { can focus on when I am presenting myself. And nobody has that } \\
\text { opportunity unless they conduct an informational interview." }\end{array}$ \\
\hline "Bright Arrow" & $\begin{array}{l}\text { "My informational interview experience was like a bright arrow that I'm } \\
\text { headed in the right direction. Whereas last semester, I was just walking } \\
\text { around campus not knowing what I wanted to do; I'm more sure now. } \\
\text { Now, I know what I need to do to reach my goal, and the internship I } \\
\text { was offered is a start. My informational interview was like a bright arrow } \\
\text { looking straight ahead, telling me to keep going." }\end{array}$ \\
\hline $\begin{array}{l}\text { "Pandora's } \\
\text { Box" }\end{array}$ & $\begin{array}{l}\text { "[The informational interview] was like Pandora's box, where the odds } \\
\text { are heavily in your favor. So there's this big black box, and you don't } \\
\text { know what is inside. It could be amazing, or it could be the worst thing } \\
\text { in the world . . because at the time, I thought I could screw it up and } \\
\text { screw up the reputation of my university. I wasn't expecting to gain the } \\
\text { knowledge that I gained, and I wasn't expecting to make such great } \\
\text { friendships and connections or be offered an internship." }\end{array}$ \\
\hline $\begin{array}{l}\text { "Reverse } \\
\text { Psychology" }\end{array}$ & $\begin{array}{l}\text { "Getting an internship offer was like reverse psychology. I was not } \\
\text { interviewing for an internship. I was interviewing the professional about } \\
\text { his job, and I left with one." }\end{array}$ \\
\hline
\end{tabular}


As revealed through the analogies, these six students explained how their informational interviews put them at an advantage for receiving an internship offer-an offer that came as a surprise to many of them. What caused all eight students to receive an internship offer when this was not the intended purpose of the informational interview assignment? In the next section, I attempt to answer this question by focusing on what happened during the informational interview according to both the students and the professionals that helps to account for these unexpected outcomes.

\section{Section Three: The Shaping and Re-shaping of Structure and Interaction}

Certain qualitative researchers have stressed the importance of looking at both interaction and structure, for to leave either one out of an analysis distorts understanding (Blumer, 1969; Burger \& Luckman, 1966; Collins, 1987). For the purpose of this study, structural conditions are viewed as conditions that are associated with the objective, format, roles, and boundaries of an interview encounter, as well as rules of engagement or conduct, and/or company policies regarding them. Interactional conditions are viewed as conditions that are associated with the nature of the interaction, such as the topic of the conversation, nonverbal and verbal communication, and feelings associated with the interaction.

Central to this study is that approximately $15 \%$ of the students enrolled in my class each semester received internship offers as a result of merely conducting informational interviews. As stated earlier, the purpose of the informational interview is to acquire information about a person's desired field or occupation, which is very different from the objective of a formal interview, which is to obtain a job. Because there is a clear objective of evaluation in the formal job interview, the "power" roles are quite distinct in that the professional is usually in control. In an informational interview, 
however, the student typically facilitates the questioning, so the "power" roles are less distinct. In some ways, the structure of a formal job interview and an informational interview are similar, in that both involve a question and answer format. But close examination reveals that the structure in the informational interview fosters a certain set of interactions that change the parameters of the encounter from the student interviewing the professional to the professional interviewing the student. Surprisingly, this change results in students receiving internships during their informational interviews. As mentioned earlier in the chapter, after the initial analysis of the data, a preliminary theory, grounded in the data, was developed to explain the interplay between structure and interaction. Subsequently, several theoretical constructs that seemed to apply to the findings were incorporated in my analysis of the data.

This section of the findings will reveal how internship offers resulted through a series of activities that shaped and reshaped the structural and interactional conditions of the informational interview (See Appendix F for a visual model). To explain the typical shift in structure that occurred during the interviews, this section will highlight cases of: 1) initial structure shaping positive interaction, 2) positive interaction shaping informal structure, 3) informal structure fostering deep understanding, and 4) deep understanding fostering an internship offer. Because all of the professionals and students interviewed claimed they had participated in a formal job interview at some point in their past, many of them naturally drew comparisons to a formal job interview when describing the structural and interactional conditions of their informational interviews. Therefore, this section of the findings also indirectly addresses the differences between formal job interviews and informational interviews. 


\section{Initial Structure Shapes Positive Interaction}

The informational interview is structured by an understanding that there is no job at stake and by the fact that the traditional interview roles are reversed, whereby the student asks the questions and the professional answers the questions. As the data suggest, both of these factors create an environment that supports particular kinds of positive interactions, specifically interactions that elicit "comfort and "flattery."

Comfort. The purpose of the informational interview assignment is to learn about a professional's career in order to fine-tune one's career goals. Without the pressure or stress of attempting to secure a job, it is not surprising that six of the eight students mentioned being comfortable. When asked how an informational interview is different from a formal interview, they reported that they were much more comfortable in an informational interview as opposed to a formal interview, where there definitely was a job on the line. For instance, one student explained:

I would be in a hot seat in a formal job interview. The difference is that I think you'd have a lot more pressure on you in a formal interview, because there's something at stake. But if you could go into a formal interview and not worry and present yourself like you do in an informational interview, that' $\mathrm{d}$ be great.

Another student discussed how he was nervous at the beginning, but his anxiety

dissipated as the informational interview progressed, because he sensed that his role was more of a client's, and there was reciprocity in helping each other. He explained:

I was actually nervous because of scheduling and making sure I got there okay. After we got going in the informational interview, I was fine. I was comfortable, and it was almost like I turned into the client, and it was like, how can we help each other? In a formal interview, I would be afraid of not knowing the answers of something I would be asked; whereas, in the informational interview, I felt like I was more in control and comfortable.

Comfort was enhanced during the interview when the student was able to concentrate on learning about another person's occupation. 
Comfort was also facilitated, as explained by five students, because roles were reversed (i.e., the student conducted the interview rather than the professional). Here, the particular structural arrangement of the interview influenced the kind of interactions that resulted. By placing the student in a position of authority or control, as he/she was the person directing the interview, a very different dynamic from the kind that typifies traditional job interviews existed between the professional and the student. For instance, one student explained she "wasn't intimidated and didn't feel any pressure," because she was the one questioning the professional. Another student described her comfort in terms of being "relaxed" because she was "running the interview":

In the informational interview, I was running the interview, and it was about what I wanted to know, because I was asking them the questions. They could tell me stories about how they could relate to me, as opposed to them asking me questions about my abilities like they would in a formal interview. In my informational interview, there wasn't the pressure of trying to answer questions correctly. It was just really relaxed.

Likewise, another student explains:

In a job interview, there's a sense of an authority kind of looking down on you. It's almost like a hearing. That's what it feels like. They are hammering you on questions, almost trying to make you mess up. Whereas, in the informational interview, I felt like I was much more relaxed and not worried about what I was going to say, because I was the one seeking the information.

The informational interview arrangement, without the perpetual questioning that usually ensues in a formal interview, contributed to a climate that made students feel comfortable. Therefore, the structural condition that supported a kind of "role-reversal" appeared to have further contributed to the climate of the interview- the climate that made students feel comfortable. In addition to the informational interview arrangement fostering "comfort," professionals reported feeling "flattered" by the arrangement. 
Flattery. The comfortable atmosphere of the interview and the fact that the professional was not responsible for hiring a new employee routinely caused the professionals to relax and to merely feel flattered by the interview. All eight students commented on how they felt that showing sincere interest in the professionals' careers and lives made the professionals feel good and willing to open up and share perhaps much more than they would have done in a formally structured job interview. One student explained it this way:

And they [the professionals] see a young person who just wants to learn about what they do and about a cool career. And I think most people would want to tell you about what they do. They'd be like, "Yeah, this career is great!" They'd have pride in it, and they would want to tell you about it. And just the fact you're asking about their career and them is really impressive to them.... I think people are flattered because you are spending most of the time talking about them. And people like that; it's just human nature [he laughs]. So people get a chance to tell students about what they do. It's sort of self-reaffirming for them ... like they are saying, "So this is what I like to do and why." So to get students really interested in what they do is kind of really flattering for a lot of people.

Likewise, another student commented:

I think people are just really grateful for other people or some random person to take an interest in what they do every day. And so they're proud of it. Like they want to show it to you and show it to you well and be honest with you. For instance, if somebody was interviewing me and asked me what it was like going to [the university], I would introduce them to professors and walk them around campus, because it's like, this is my life, and if you're that interested I will show it to you. So I think they [the professionals] are excited like that.

It was not only the students who thought the professionals felt flattered. The professionals explained the experience similarly. Five of the eight professionals confirmed the students' feelings. One professional explained how it was an honor for someone to come and ask for information from him, saying it gave him a "sense of selfactualization." In the interview, he also shared the idea that it is important to make professionals, like himself, feel good in an informational interview. He reinforced this 
sentiment by offering advice as to how students should approach someone for an informational interview:

A little flattery goes a long way, but it's not flattery for flattery's sake, you know, if it comes across as fake . . . not good. But I feel like if [the student] can give a professional a little ego boost, it makes them that much more available to you. Because they recognize that you are showing them some sort of respect . . you know you're recognizing that they are busy people, and you recognize that they are doing their job and they might actually not have time for you, but if you stroke a professional's ego a little bit ... it opens up doors very quickly. You ask if you can come out and interview them and say, "I wondered if you'd have any time, because I think it would be an invaluable part of my educational experience to learn what an accountant of your caliber thinks, and I can really pick your brain and see what you're doing from day to day."

Another professional confirmed feeling somewhat flattered by the informational interview and commented that it was great to talk about her job and to be able to tell someone why she likes her job. She explained that she does not get many opportunities to talk to people about why she loves her job, and this opportunity allowed her to do that

Being able to talk about the positives of their jobs seemed to motivate the professionals to share much information. Of some surprise to five of the eight professionals, this opportunity provided some reflective time that they typically did not have but that they found very valuable. For example, one professional explained, the informational interview added to his own understanding of what he does and why he does it:

I think it's always wonderful to think about the good part about my work, and it's nice to know that young students are inquisitive and asking, if you will, probing questions, and it really requires a lot of time for the business executive to kind of sit back and reflect and say, okay, so what is my business all about? It gives us a little more understanding of our own business as we try to share this with people who don't have a full comprehension of what goes on, in my case, the symphony world. So I found it very helpful. 
Another professional said that having someone listen to his aspirations made him feel good: “And sometimes, I just feel it's good to hear yourself talk out loud about your job and where things have been going. It's nice to have someone to listen to you."

It seems the structure of informational interviews that allowed for roles to be reversed provided interactional opportunities for the majority of the professionals to feel flattered - apparently something they not only appreciated but felt was missing in their professional lives.

Not having a job on the line, as is typically the case in a formal job interview, also contributed to creating a comfortable climate in the interview - a climate allowing for students to praise and listen to these professionals without the fear of evaluation. This positive interaction served to reshape the structure of the informational interview in ways that promoted even greater informality.

\section{Positive Interaction Shapes Informal Structure}

Due to the positive interactional conditions of "flattery" and "comfort" produced by the initial structure, the structure of the informational interview began to shift to even greater informality. While the students were prepared to ask their set list of questions and spend twenty minutes of time with the professional, the students were pleasantly surprised to find the informational interview context quickly led to the professionals being willing to give more time and to engage in informal dialogue that was initially not anticipated by the student.

Flexibility with time. This informality motivated by the factors described above led to the students receiving a greater amount of time from their professional than scheduled. Instead of receiving twenty minutes of the professionals' time, seven of the eight students mentioned that they were very surprised by the fact that their informational 
interview went longer, in two cases up to three hours. One student, who ended up having a three-hour informational interview with his professional, explained that although they were frequently interrupted, the professional was incredibly generous with his time:

He was willing to give so much of his time, because the interview was at his office. His secretary was over there, and they were kind of yelling at each other back and forth: "Hey, so and so is on the phone and they need ..." So he had a full day going, and it wasn't his lunch break or anything, so that was the number one surprise for me-that he was willing to give so much time while being very busy. A guy even came up and held a poster up and said, "Hey, what size do you want these fonts?" And he said, "Yeah, just switch that around," and you know, it was just funny seeing that going on. It was so nice- he gave me so much time, and it was cool to see him doing everything and then just focus on me.

Two students noted how the professionals turned their computers around and showed them their calendars. They indicated that they were surprised by how much detail the professionals were willing to share. One student, for example, stated:

I asked her, what is your typical day like? And she took her computer and like turns it around and it was jam packed with stuff, like the next week she was flying to France for three days to deal with a client, and like all of this stuff. I was just so shocked she took extra time out of her day to show me that.

The connection between the professionals feeling flattered and their willingness to give so much extra time was apparent to five out of the eight professionals as well. One professional, for example, noted the connection between his enjoyment with talking about himself and his willingness and need to be thorough in his answers-which of course translated into a longer period of time than was anticipated. When asked about why his interview with the student went much longer than the twenty minutes the student requested, this professional stated:

Honestly, because I can't stop talking. There's nothing else to say [he laughs]. I just love to hear myself talk. I wish there was more than that. Again, I feel like there is so much information I want to share. The questions are broad, so they're not going to be short answers. And I'm not going to shortchange the kid and be like, "Oh, listen, I've got an egg timer on my desk, and you've got twenty minutes." I feel like I want to give the kid the right answers, not, "Oh, your 
twenty minutes is up, I got to go." I'm not going to give one-word answers. That's not the way it's going to be for me. If I commit to doing it and I tell the kid, "Yeah, I'm going to sit with you and talk to you," I'm not going to be like let's hurry up man, I've got a phone conference in twenty minutes. I wouldn't schedule it if that was the case. That's the way I operate. There's a lot of information to share, and I want to tell the "right" answer. And again, I talk a lot.

Likewise, when asked about why his interview went longer than the scheduled twenty minutes, another professional explained:

Probably because I like to hear myself speak [he laughs]. No, I think the student asked some very probing questions, and we were really talking about the depth of the business. Trying to explain anything in twenty minutes, especially in this area, which is a very complex area, is something you just can't do. And so when the student shows an interest, and I think they need clarity on what I'm saying, it takes a few more minutes.

The need to "tell the right answer" when asked a question seemed to be important to several of the professionals, who explained that because what needed to be said could not be done in a mere twenty minutes, they were willing to allow the interview to go longer.

Positive interactional conditions clearly led to flexibility with time boundariesthis was shown in large part by the comfort level of both students and professionals, as well as the flattery felt by the professionals due to the students' attention and desire to learn about their work. Interestingly, these conditions also helped create a different kind of dialogue than what is found in most job interviews - a dialogue that became more like a conversation than a formal interview.

Permeable dialogue boundaries. Instead of being a strict question and answer format, indicative of most formal interviews, seven of the eight students who participated in the study noted that the interview was very conversational. Dialogue boundaries appeared to become permeable. Seven of the eight students, in fact, noted that the professionals did not always directly answer the question asked. Instead, the professionals went off on tangents, with the communication frequently interrupted by 
phone calls or other employees. This seemed to work to the advantage of the students, who explained that they learned "a lot" from the interruptions and deviations in dialogue.

One student commented on the dialogue that ensued between himself and the professional:

I was like, so what do you do? I felt like I kept asking that question, and she would just go off on a random tangent and tell a story that had nothing to do with the question. And I learned a lot about her job that way, because the stories were interesting.

Another student noted that informational context promoted informal dialogue, which

allowed for a more intimate connection between himself and the professional:

For my informational interview, I had questions prepared, and I was interviewing her rather than her interviewing me. However, there was really no formal structure. And just with the question itself, there was no strict way to answer it. We can go off on tangents, tell random stories, dive deep, and get personal. Because in a job interview we can't just open up about our personal lives, because you want to be professional and businesslike. But in an informational interview, it's still professional, but I've noticed that there's a more intimate connection that the two people (student and professional) have with each other.

The professionals also recognized that their responses jumped around and lacked a clear structure, functioning like a conversation as opposed to a more formally structured question and response session. One professional, for example, noted his answers "flowed into other areas." Another professional said, "Well, I think there is the freedom to go on any rabbit trails that might come up. I mean, I think, obviously, I answered questions, but I also brought up a few topics that I thought might be important to where the student might be going." Two professionals specifically noted that they were busy doing other work while the student was interviewing them about their job, thus revealing the informality of time boundaries and dialogue.

Another professional alluded to the permeable dialogue boundaries of an informational interview by describing how and why his "guard" was down: 
My guard is way down in an informational interview, because it's a completely different dynamic from the outset. It's much more conversational, as I think all interviews should be. It's much less confrontational than an interview for a job. It's like two people coming together to talk to each other rather than a question and answer format. And I think that's invaluable. I really think that the traditional way interviews are done doesn't allow the employer to see the person as they are; you see some canned answer.

When explaining his appreciation of the permeable dialogue boundaries of informational interviews, another professional expressed his frustration with the barriers posed by formal job interviews in terms of accurately assessing a job candidate:

Unfortunately, I don't know how we stack up against other companies out there, but our percentage of success in formal interviews is really not very good. We've had quite a few people who we've brought in here that just have not worked out. It's really frustrating in a way, because you sit with people, and it's just so hard to get a "read" on people. You read their résumé and know they've doctored it up a bit. It's just hard to really know them through a formal interview.

The fact that the interaction was more like a conversation allowed the students, as well as professionals, to probe more deeply and learn more than if they had been constrained by a strict question and answer format, a format typical of most formal job interviews. The findings also reveal how the informal structure, characterized by flexibility with time and permeable dialogue boundaries, facilitated a deep understanding between the students and professionals through discovering each other's values.

\section{Informal Structure Fosters Deep Understanding}

All eight students and eight professionals reported that the reason for being offered and for offering the internships was due to the fact that they had experienced interactions that led to an understanding and awareness of each other's passions, values, and similarities, or what this study will refer to as "deep understanding." This understanding appeared to be an extremely important condition of the informational interview. The term "deep" is used to describe the understanding that was generated 
between all eight students and eight professionals. The nature of understanding that resulted from the informational interviews stretched beyond surface-level knowledge of the individuals involved. Both students and professionals noted that their informational interviews allowed for a personal connection that led to a deep level of understanding in terms of 1) discovering co-membership and 2) detecting values such as passion, professionalism, and integrity/work ethic.

Discovering co-membership. After the initial analysis of data was completed for this study that revealed the significance of "deep understanding" in generating an internship offer, it became apparent that the theoretical construct of "co-membership" described in previous research by Erickson and Schultz (1982) helped explain the outcomes of these interviews. As previously mentioned in Chapter One, co-membership involves discovering what each of the participants in the interview had in common. In their 1982 study of the interactions that occurred between counselors and students, Erickson and Schultz discovered that when the counselor established that there was something that he or she shared with a student-when a high co-membership existedthe counselor became an advocate for the student. Co-membership could be anything from graduating from the same school to having the same interests. To summarize, Erickson and Schultz (1982) found that co-membership often led to favorable evaluations by counselors and positive outcomes for students.

In this study, co-membership created a "hook" that initially facilitated a connection between the student and professional and initiated a deeper level of understanding between the two. Consequently, the findings in the next section weave in a discussion of how "co-membership" was established through an awareness of each 
other's values. When students and professionals exposed their values and shared those values, interview outcomes were influenced significantly.

Emphasis on values. All eight students explained how a discussion of values surfaced during their interviews with the professionals. Several students noted it was difficult to even get professionals to talk about their day-to-day duties. Instead, the professionals wanted to share their beliefs and ideologies. One student, for example, explained the professional's tendency to focus on values in the informational interview:

[The professional] didn't really cover specifics of his job. One of my questions was, "Can you give like a specific rundown of how your day goes?" and he never really hit on that. I mean, he's a Christian, so our discussion was God-centered first, and then he just kept pulling out things and said, "If you're passionate about something - it's kind of like baby steps and micromanaging your time - and pursuing your passion. Then you'll be set."

A focus on values somewhat surprised all eight students, but it also seemed to help the students get to know the professionals better than they would have in a formal job interview, where the typical focus would be on job qualifications.

Likewise, all eight professionals shared that values surfaced in their informational interviews with the students. Some even suggested that this occurrence was anticipated. Many professionals revealed that they had something in mind to share with the students - they had some advice to pass on to them. They claimed their answers to the students' questions were often not associated with details of their job, but instead were about imparting values and providing life lessons. This also involved them noticing the students' values that were similar to their own. According to the students and the professionals, the values that surfaced most often that created a sense of co-membership included: passion, professionalism, and integrity/work ethic. 
Passion. Two of the eight students noted passion surfaced in their interview with the professionals, and seven of the eight professionals specifically cited passion as a very important value. One student recognized that his professional was impressed by him because he showed passion in terms of his willingness to learn: "[The professional] could see that I was a really well-rounded, ethical, Christian student who is passionate about learning and growing and taking in information." The student believed that their connection on this value may have made him look good. When asked why he received the internship offer, another student explained that the professional could see how "passionate" he was about working with youth. They went on to talk for three hours.

For seven of the eight professionals in this study, passion was an important part of how they conducted their jobs, and, consequently, something they valued in others. One professional stated, 'I'm big on passion. People need to be passionate about what they do-in the sense that people are passionate and step up to lead things like committees and groups. They don't have to be told to do it."

When the professionals recognized that the students who were interviewing them had passion, they became even more excited to share information about their fields with the students, for they realized the students were truly interested and not just completing the informational interview to fulfill an assignment requirement. One professional commented, "I think I saw right off the bat that Jacob was someone who has a passion for this field. If he's interested, he doesn't just talk about it — he does something." This same professional noted that not all of the informational interviews in which he has participated have gone very well, primarily due to the students' lack of passion: "Some students come and ask to do an informational interview for a class, and at times it can be more of a burden more than a blessing." He explained that it was a burden when the 
student did not know what he/she wanted to do and was just doing the interview to fulfill an assignment. He pointed out that Jacob was different, because he was clearly passionate about this career field.

Another professional who noted the passion in her student was impressed and surprised by the simple fact that the student took the initiative to conduct an informational interview. The professional said she was more motivated to offer the student an internship than if the student had come looking for an internship:

[The informational interview] helped him get the internship because it was a serious thing, meaning he's actually doing something to show he's motivated rather than just coming out and trying to get an internship. I guess to me, I hadn't seen [an informational interview] before, and it was really on a different level. It was more of a learning experience, and I always enjoy that, too.

Similarly, one professional noted her student's passion when the student displayed an eagerness to ask questions. She expected this kind of behavior more from someone who was already an intern, versus someone just doing an assignment. She went on to explain how the types of questions the student asked dealt with learning about the downsides of the job, not just the upsides. She was impressed by the student's passion for knowing all facets of the job and said this contributed to her belief that the student would make a great intern.

In addition to passion, professionals were impressed when students presented themselves in a way that demonstrated they valued professionalism. Exposing this value provided another opportunity for the student and the professional to realize their shared attributes.

Professionalism. Four of the eight students and four of the eight professionals stressed the importance of professionalism. Professionalism was understood here in terms of professional dress, preparation, timeliness, and proper etiquette. When one student was 
asked how he showed professionalism, he said, "Just by being prepared and organized." Another student pointed out that being professional allowed her to receive respect from the professional: "Ultimately, you walk in there looking professional, so they treat you professionally. So to have that experience-because you're not put in that position very often-was something new and something really, really cool."

Valuing professionalism and noting it in others helped the student and the professional realize and benefit from the phenomenon of co-membership. In the following interview transcript excerpt, one professional describes his student's professionalism and the important role it played in his assessment of the student:

I think the informational interview was excellent. The student was a very nice fellow, he was well-organized, he had questions he wanted to ask, you know, and he would kind of take it in a logical step. And he followed it up with the thankyou card. You know, all of the things you just need to do - the attention to detail. And so when I am willing to give time to somebody, it is very important that they are prepared, and if they're not, I just don't have a lot of time for it. He came in here and was properly attired, properly presented, and well-organized, so I think he did a wonderful job, and that's the way you need to be.

Another professional was impressed when the student who interviewed her delivered a hand-written thank-you, with a gift card to a fast food restaurant the professional had told him she enjoyed placed inside of the card. She was also impressed by the fact that the student personally delivered the card and the modest gift to the professional's place of business. These actions not only reinforced her belief that the student was interested in what she had to say and had really paid attention to the details of their discussion, but also that the student valued professionalism. She indicated that the student's efforts to express appreciation went beyond her expectations and created a positive impression about the student's professionalism. 
Similarly, another professional noted the importance of professionalism in making a good first impression:

You never get a second chance to make a first impression. If you are interviewing with a professional, everything you do is something they will remember. Don't burn bridges; don't make bad impressions, because when you talk to somebody else, everything you do is an interview. You don't want to show disrespect by sitting there in a t-shirt and jeans. Everything is an interview, even an informational interview. If I would hire this person, you can see how they'll represent you. When they talk to clients on the phone and say "dude," I think, "How unprofessional." When you are student, is it really that much to ask a roommate to borrow a tie? Is it worth not getting an internship and not even the chance because of your hair? Dress for the job you want to have.

Finally, another professional spoke about the importance of professionalism to her by remarking that the student was early and prepared. She said "punctuality, professionalism, articulation of questions, and follow-up questions are all very important things."

In addition to displays of passion and professionalism, when students offered a clear indication that they had integrity and a strong work ethic, they and the professionals they interviewed had another opportunity to establish shared values.

Integrity/work ethic. Three of the eight students mentioned that the professionals stressed the importance of integrity and having a strong work ethic-values that they too held in high regard. Furthermore, their comments suggest that they were straightforward in sharing their commitment to these values with the professional. One student explained:

[The professional] talked about character and integrity and stuff like that. He is having to deal with managers that are just really rude and mean to him, and he has to talk to them every day. So he said that's like a big deal ... "If you're nice to me, I'm going to be nice to you." So he said how you act and the way you do your job really reflects on how people are going to act towards you.

Another student noted that he felt the professional (an alumnus from the same university the student attended), was impressed with his questions dealing with integrity. 
They established a connection-a co-membership-grounded in their common

educational background and grounded in the fact that both were Christians. The student explained:

I think the professional was impressed with me asking professional questions. But I also tried to get to more of a personal level too and to find out how the job fit with his morals, values, and integrity. For instance, he told me that he was a Christian, and so I wanted to know how that fit into the real estate realm and if it challenged his ethics and integrity.

Four professionals also mentioned the importance of integrity, a strong work ethic, and the need to pass on to the students the lessons associated with these values. For example, the professional referred to in the previous quote explained that being an alumnus from the same Christian college the student attended allowed for a greater level of trust: "I went to [the university] due to values, and, overwhelmingly, I've found that the caliber of student at [the university] is on a personal level a higher caliber from other universities." He added that while other institutions may be more academically challenging, he would trust a student from his alma mater more due to their values.

Another professional noted that these lessons were more important than talking about her job duties:

You know .... I just wanted to talk to Jamie about my job-it really has nothing to do with what I'm actually doing, but instead I like to talk about developing people, building up succession, so when Jamie asked about what I like about my job and what keeps me in my job, it's always about the people and it's always about developing someone else. I talk to Jamie mainly about the intangibles in my job. My highest factor with people is very much integrity, so I could not like the person, but if they have very high integrity, I could be successful working with them. If we have different styles, we could play off of those styles. I mean, you may not like the person, you may not say, "They are my best friend." But with very high integrity, you can work on projects with them, and in accounting, where you need different skills to do stuff, you can be very successful if the person you work with has high integrity. 
The informal structure of the informational interview led to an understanding between the professional and the student-an understanding that occurred at a deeper level because it exposed values of each. Because the participants were able to achieve this deep understanding, the organizational structure was reshaped in a way that motivated an internship offer.

\section{Deep Understanding Fosters Internship Offer}

A radical shift in the structure from the student interviewing the professional to the professional interviewing the student occurred as a result of the informality and deep understanding created during the interview. All eight professionals in this study offered an internship opportunity to their student interviewers, and the professionals served as advocates for the students. This section examines why the shift in structure occurred from the perspective of the students and from the perspective of the professionals who were involved.

\section{Informational interview "trumps" a formally structured interview. In}

addition to the impact that establishing a sense of co-membership in terms of values had on the likelihood that an internship offer was made, organizational factors also played a role in the professionals' ability to offer internships. Specifically, the size of the professional's organization appeared to influence the extent to which the professional was able to hire a student. For instance, six of the eight professionals mentioned that they had the freedom to offer the student an internship because they were either working at a small company or they were the owner of the company. Although two of the professionals mentioned that their students would still need to go through a formal interview to secure the internship that he/she had offered them, these students would definitely be at an advantage, having done the formal interview with them. These two 
professionals both mentioned they would talk to the person from their department responsible for formally interviewing the student and pass on a recommendation to hire the student. One professional noted that the student would still need to go through the same interview process as everyone else, but that the student would be at an advantage, having gotten an inside glimpse-some insider information-about the company through her informational interview. One student noted the advantage she gained from the informational interview. When she arrived at the formal "internship interview" at the company where she had conducted her informational interview, the first words the professionals uttered were, "So when do you want to start?" She explained that there was no formal interview process; it was as if she had already gotten the job. The formal interview was more of a formality. Here it is apparent that the informational interview appeared to "trump" the formal interview process in that these students benefited from their ability to have gained familiarity with the organization, and more importantly, to have established co-membership with an organizational member who was in a position of power and able to make such hiring decisions.

Shift in structure. In the informational interview, the students were cast in the role of "interviewer." When asked how the internship surfaced, however, four students noted there was a shift in the structure of the interview from them interviewing the professionals to the professionals interviewing them, as if there was a job on the line. According to Turner (2009), "a change in one's role reflects a changed assessment or perception of the role of relevant others" (Turner, 2009). A role shift indicating an assessment was at play happened when the professional shifted to the role of "interviewer" and showed interest in the student as a potential intern. The students said 
this shift in structure was surprising, yet very obvious. One student, who interviewed a summer camp director, said:

It was funny because he interviewed me for about thirty minutes after his interview. So he just started interviewing me and, just off the top of his head, he started asking me some questions, and then he was like, "So if you would be interested in an internship, I'll get you in the office and see how you like it for about half a year, and, then, when camp gets ready to start, then maybe I can offer you a position."

Another student revealed his surprise when the professional took extra time at the end of the informational interview and shifted the focus to him, the student:

My interview went about thirty minutes, which is kind of funny because he made it like really obvious at the beginning when he said, "I have to be out of here in twenty minutes," because he's a really busy guy. So, the fact he'd take an extra ten minutes to ask me about myself is really cool.

Interestingly, all eight professionals mentioned the role shift that occurred during the interview. For example, one professional explained that even though the student was cast in the role of "interviewer" for this encounter, he also interviewed the student. There was a "reverse-interviewing" process going on simultaneously with the student-directed informational interview. He explained the interviewing process as two-directional, in that the professional interviewed the student in addition to the student interviewing the professional.

Another professional stated:

It's good for me to go through being interviewed, but it's also interesting because at the time of year that the student came in to interview me, there is also the opportunity to interview the student. She's learning about our company and meeting people, but we are also learning about her. It's her opportunity also. So the way it's kind of set up, there's reverse interviewing as well.

This notion of "reverse-interviewing" is critical to understanding the nature of the informational interview and how it serves as a means to acquire employment. It is especially intriguing to note that students and professionals did not, at least initially, see 
the informational interview functioning as a formal job interview, for it was clearly an assignment designed to help the students fine-tune their career goals. But, as the professionals' formal questioning of the students began to evolve serendipitously by the end of the interview, after they had gotten to know each other better, it seemed natural for the professionals to consider offering the students internships.

One might assert that because the structural and interactional conditions of the informational interview allowed for a deep understanding between the professional and student, the professional became more interested in the student as an employee. One could also contend that the informational interview served as a "hook," in that it was a way for the professional and student to get to know each other before any consideration of employment. This "hook" provided an advantage for the student in securing an internship, and ultimately trumped the formal job interview process that was, in some cases, required even when a company was filling internship positions.

Interplay between structure and interaction. According to all eight students and seven of the eight professionals, having a deep understanding of each other is what led to an internship offer. It seems the shift in the overall structure occurred as a result of an interplay between structure and interaction. The structure was sufficiently informal from the beginning to construct a series of interactions between students and the professionals that prompted a sense of co-membership-a sharing of values including passion, professionalism, and integrity/work ethic. It was not merely the interactions that ensued during the interviews that accounted for the positive outcomes. It was the fact that the interactions were embedded in a structure that was flexible and able to change.

The model displayed in Appendix F helps to explain the interplay between structure and interaction that occurred during the informational interview. It shows how 
the initial structure (no job at stake and role-reversal) created conditions that allowed positive interactions to take place-interactions that led to professionals feeling flattered and comfortable. These positive interactions appeared to stimulate the professionals' willingness to be flexible with their time and to engage in a dialogue where boundaries were permeated and personal values and feelings were exposed. As a deep understanding between the professional and student evolved, a relationship was created that has been described as one of co-membership through the sharing of mutual values. Ultimately, because they were able to gain a deep understanding of each other, there was an obvious shift in the interview arrangement. By the end of the interview, the professionals were asking questions of the students and, in many cases, offering internships.

Findings from this study of informational interviews indicate that in order to understand their successful outcomes, it has been essential to take into account the interplay between the structure of the event and the interactions that ensued as they continually influenced each other. 


\section{CHAPTER FIVE: DISCUSSION}

Because three-fourths of job openings are not advertised and are filled through the hidden job market, it is apparent networking plays a major role in filling these job openings. Because the informational interview is one form of networking, this study serves as an initial understanding of the structural and interactional conditions involved in internship offers initiated through a specific kind of networking and provides insight into why networking may "work" better as a means of securing employment than a formal job interview. The National Association of Colleges and Employers claims that the same old approach for securing a job is not likely to work in this economy (NACE, 2009). This statement, along with this study, may lead more people to ask themselves if their "net" is working.

According to the research on internships, the value of an internship in securing full-time employment is supported by the National Association of Colleges and Employers, which indicated that more than $50 \%$ of all job offers from reporting companies were made to former interns within those companies (WSN, 2010), up from $36 \%$ in 2009 (Bryan, 2009). Furthermore, according to a recent survey of companies looking to hire college graduates, $49 \%$ claim that they offer higher salaries to those students with internship experience (Normington, 2011). The Wall Street Journal indicates that taking part in internships improves a student's employment prospects after college (WSN, 2010), and the National Association of Colleges and Employers states that students without internship experience "have unrealistic views of work, lack maturity and work ethic, lack commitment to the organization, and possess less awareness of business etiquette" (as cited in Normington, 2011). 
With this recent realization of the value of internships, the process of securing an internship has become very competitive-so competitive that some students are even turning to fee-based internship programs to secure internships (Normington, 2011). The Washington News Square reported that "the dismal economic climate necessitates providing every possible resource to students bound for the job market-helping students find internships is, now more than ever, a huge part of that" (WSN, Sept. 2010). With this in mind, it appears that securing an internship plays a vital role in securing employment. It seems important, therefore, to understand strategies that can enhance opportunities to secure internships. This study suggests that discovering and being offered such internship opportunities may, in some cases, result from one form of networking-informational interviews.

After conducting a thorough review of literature on the subject of networking, I found no theoretical explanations offered as to why networking is so successful in securing employment. This study addresses this issue by looking at how one form of networking, informational interviews, was successful in leading to internship offers. Based on the findings, this chapter draws some conclusions about this issue by highlighting 1) how informational interviews create an ideal networking tool due to the structure and interaction that ensues in this context; 2) how informational interviews address many of the limitations of formal job interviews; 3 ) implications for employers, job seekers, and educators; and finally, 4) future areas of research.

\section{Informational Interviews as an Ideal Networking Tool}

This study is a beginning step toward constructing a more general theory of networking, more specifically, networking that promotes job offers. The findings presented in the previous chapter focused on what happened in eight informational 
interviews that led to students receiving a bit more than information: They received an internship offer. Therefore, this study examined how one form of networking, the informational interview, provides a structure that enhances a particular kind of interaction that leads to an internship offer. However, as revealed in the model presented in Appendix $F$, the interaction leading to the internship offer was ultimately molded through a process involving the shaping and re-shaping caused by the interplay between structure and interaction. Ultimately, a deep understanding between participants surfaced that, in turn, led to a structural change-from the student as an "acquaintance" to the student as a "desired future employee." This study also revealed the importance of the construction of co-membership and an understanding among participants at a deeper level than typically occurs in a formal interview. Respondents in this study were clear that the opportunity to expose a shared sense of values fostered an internship offer.

\section{Initial Theory of Networking}

As revealed in Chapter Four, this study provides evidence for the structural and interactional conditions involved in an initial theory of networking leading to job offers. This "theory of networking" is an explanation of how structure and interaction work together to create an informal setting wherein a deeper understanding is achieved. Structural conditions include: 1) no job at stake, 2) reversal of roles (equal to each other), 3) permeable dialogue boundaries, and 4) flexibility with time. Interactional conditions include: 1) level of comfort, 2) opportunities for flattery or other-directed ingratiation, and 3) understanding at a deep level (values/co-membership). These conditions and the interplay between them serve as components for an initial theory of networking leading to job offers. 
As revealed in Chapter Four, the model displayed in Appendix F helps to explain the interplay between structure and interaction that occurred during the informational interview. It shows how the initial structure (no job at stake and role-reversal) created conditions that allowed certain kinds of interactions to take place--interactions that led to professionals feeling flattered and comfortable. These positive interactions appeared to stimulate the professionals' willingness to be flexible with their time and to engage in a dialogue where boundaries were permeated and personal values and feelings were exposed. Students were able to share their values with the professionals, and a deep understanding between the professional and the student evolved. There were able to create a relationship that was grounded in a sense of co-membership. Ultimately, because they were able to gain a deep understanding of each other, there was an obvious shift in the interview arrangement. By the end of the interview, the professionals were asking questions of the students and offering internships.

Findings from this study of informational interviews indicated that in order to understand their successful outcomes, it was essential to take into account the interplay between the structure of the event and the interactions that ensued, as they continually influenced each other to create an informal context wherein the students and professionals were able to connect at a deeper level-a connection that goes beyond what normally would occur in any type of interview.

\section{Application of Theoretical Constructs}

Two key theoretical constructs that contributed to the explanation of this theory include: 1) structure and interaction, and 2) co-membership.

Interplay of structure and interaction. The support for looking at both structure and interaction in the informational interview context allowed for an understanding of 
how an informational interview, on the surface, seems to be solely about gaining information, but in reality is much more. By exposing the interplay between structure and the conditions it creates as well as the interactions that occur in this context, the informational interview was found to be an effective networking tool.

As discussed in my literature review, many early researchers looked at both structure and interaction, but they placed less emphasis on structure (Berger \& Luckman, 1966; Garfinkel, 1967; Blumer, 1968). Some that examined structure and interaction purposefully violated social norms or rules (structural conditions) in order to expose the impact of structure on interactions (Garfinkel, 1967). Garfinkel wanted to show society that rules are shaped and supported by their interactions. He argued that when society violates those rules, they truly see the prevalence of them.

Collins also called for a focus on both structure and interaction and argued that attending to both is helpful in understanding the events. He stated: "The effort to connect the macro [structure] to the micro [interaction] is worth making as the power of explanatory theory on either level will be enhanced if we can show their mutual penetration in a fairly precise way" $(1987$, p. 195$)$.

This study accomplished this exposure from the outset, for the informational interview violates social norms or rules of engagement for an "interview." In an informational interview, the student is interviewing the professional, and there is no job at stake. It is definitely not your typical "interview," in that roles are reversed, and the structure fosters a more informal setting where meaningful interactions between interviewer and interviewee are nurtured.

Advocacy through co-membership. While this study reveals that an interplay between structure and interaction led to the internship offer, the theoretical construct of 
"co-membership" helped to shed additional light on why the professionals ended up serving as advocates for the students.

As mentioned previously in Chapter Two, Erickson and Schultz (1982) used the term "co-membership" to describe the discovery of shared attributes, status, or common interests in interview context. They found that the small talk that was able to occur between counselors and students led to the discovery of co-membership, and counselors were more likely to help out students who held similar interests to them. They recommended more counselors engage in small talk with students and, instead of viewing it as "wasted time," to view it as a chance to discover "co-membership," that is, to discover what the counselor and students have in common. When counselors discovered "co-membership," the counselors were motivated to serve as advocates for the students.

Erickson and Schultz's research has been particularly useful in helping to explain the success of the informational interviews. The findings from this study, however, extend their work by exposing the importance of establishing shared values in such relational opportunities. Although their study identified the importance of individuals connecting on similar interests, such as when a counselor enjoys baseball and his student advisee is a baseball player, they do not specifically identify "values" as contributing to high levels of co-membership.

Similar to the counselors and students in their study, it appears that the students from my class who connected with the professionals were advantaged. Professionals advocated for them by offering an internship and/or placing the student at a vantage point in an interview process that would put them in a position for an internship. The subsequent internship offers are evidence of the professionals' advocacy of the students. 
This type of advocacy is something most job seekers dream of, but unfortunately, cannot achieve very easily through the formal job search process.

In having the structural support for the professional and student to uncover their common values - values such as professionalism, passion, and work ethic/integrityprofessionals and students deepened their understanding of each other. Relating at this level provided the kind of network connection that supported career opportunities for the students involved.

\section{Informational Interview vs. Formal Employment Interview}

In Chapter Two, I reviewed many of the limitations of formal interviews, such as inaccurate assessment (Kirkwood \& Ralston, 1999; Hunter \& Hunter, 1984), heightened anxiety (McCarthy \& Goffin, 2004; Posthuma, Morgeson, \& Campion, 2002; Yuen, 1998), lack of understanding beyond surface-level demographics (Wayne \& Kacmar, 1991; Helgesen, 1995), and few opportunities for interview ingratiation (Tsai, Chen, \& Chiu, 2005; Higgins \& Judge, 2004; McFarland, Ryan, \& Kriska, 2002). In Chapter Four, I provided descriptions of students' informational interview experiences and discussed how students and professionals naturally drew comparisons to the formal job interview context. Their comparisons contributed a greater understanding of the differences between the two "interview" settings. They revealed how informational interviews rectify many of the limitations of formal interviews highlighted in the literature review.

\section{Differences in Anxiety}

As previous research has shown, anxiety levels tend to be higher during job interviews, as applicants are worried about having the "right" answer, and there is a job at stake (McCarthy \& Goffin, 2004; Posthuma, Morgeson, \& Campion, 2002; Yuen, 1998). Students in this study reported low levels of anxiety due to the fact there was no job at 
stake during the informational interviews. Additionally, they mentioned that they felt comfortable because they were primarily in control of the informational interview. As revealed in Chapter Four, students used terms like "hot seat" and "on trial" to describe the anxiety associated with a formal job interview. In contrast, informational interviews were described as fostering a comfortable atmosphere due to the structural conditions of role-reversal.

\section{Differences in Ingratiation Opportunities}

The structural conditions that characterized the informational interviews led to a reduction in anxiety and also provided opportunities for the students to flatter the professionals by inquiring about the professionals' occupations. Unlike what happens in a formal employment interview, during which an applicant's ability to use other-directed ingratiation techniques (i.e. flattery, agreement on values/opinions) is limited, professionals in informational interviews are able to use techniques that put a student applicant at an advantage (Tsai, Chen, \& Chiu, 2005; Higgins \& Judge, 2004; McFarland, Ryan, \& Kriska, 2002). This research has also revealed that if one shows interest in a person or has similar beliefs, feelings, and values, others feel good (Wayne \& Kacmar, 1991). Students and the professionals involved in this study spoke repeatedly about how the informational conditions of the interview significantly fostered opportunities for ingratiation. As indicated by the responses of students, professionals felt flattered by being asked questions about themselves, and all eight professionals confirmed feeling flattered in their informational interviews with the students. Flattery in the informational interview process was key to professionals being willing to extend interview time and in creating an opportunity for interactions to occur at a deeper level. 


\section{Differences in Level of Understanding}

Professionals and students were clear that permeable dialogue boundaries and an extended interview time led to more information being shared and to a connection on a deeper level. In a sense, it allowed for the student and professional to be more "other" centered, which, according to Helgesen (1995), is the key to forming networks of contacts. Formal interviews, usually time-bound and scheduled back-to-back, do not allow for such freedom in dialogue. The findings of this study revealed that both students and professionals noted that the permeable dialogue boundaries led to a more conversational style of interaction rather than the strict question-and-answer format typical of most formal job interviews. As previously noted, one professional explained that his "guard" was down in the informational interview, and a student pointed out that the professional went "off on tangents" and "shared values," which led to a broader and deeper understanding of each other.

Informational interviews provide a structure that allows for a more conversational format with flexible time boundaries - a structure that leads to a more accurate assessment of another person-and a structure that is lacking in the formal job interview.

\section{Differences in Assessment}

Due to the fact that formal interviews are time-bound and usually employ a question-and-answer format, it is somewhat difficult to deviate from the set questions and simply get to know the job candidate at a deeper level (Kirkwood \& Ralston, 1999). Research by Hunter and Hunter (1984) reveals that the validity of the formal job interview (assessing work potential in a job candidate) varies from setting to setting and that overall the validity of the formal interview is relatively low. They claim that the validity of the formal interview differs according to some organizational feature not yet 
identified. In other words, they claim uncertainty as to what feature is missing in a formal interview that could help to more accurately assess a job candidate. Could it be that validity is increased when questions are directed at really getting to know the job applicant, such as in an informational interview, in contrast to a formal interview, where questions are directed specifically at assessing if the job applicant can fulfill the job duties? For, in most traditional job interviews, the focus is on finding out the knowledge and skills of the candidate as they relate to a particular position and less about the candidate as a person with values and dispositions.

This research reveals that the informational interview allows a student and professional to get to know each other beyond his/her skill set. By tapping into someone's values, an employer can more accurately assess job "fit." The informational interview may provide the missing "feature" that Hunter and Hunter's 1984 study claims must be identified in order to improve the reliability of formal interviews. Without the opportunity to connect or understand at a deeper level, the employer plays the role of Sherlock Holmes, trying to deduce the truth from what may be the interviewee's "canned" answers constructed to respond to commonly asked interview questions (Kirkwood \& Ralston, 1999). As one professional noted, in a formal job interview, it is difficult to get "a read on people." In comparison, an informational interview allows for the opportunity to get to know a prospective job candidate much better.

\section{Summary}

The literature review clearly indicated that the formal employment interview process creates many barriers in getting to know a job candidate at a deeper level. As a consequence, many employers hire employees who are not the right fit. In turn, employees take on jobs that are not the right fit for them and, consequently, change jobs 
frequently. This section has highlighted how the informational interview process tends to avoid many of the problems that have been associated with the formal job interview process and provides both the interviewer and the interviewee a deeper understanding of each other.

\section{Implications for Employers, Job Seekers, and Educators}

As discussed in Chapter Two, the average person changes jobs every five years or up to 10 times in his/her lifetime (U.S. Department of Labor, 2010). Furthermore, an employer interviews an average of six applicants per position (Barron, Bishop, \& Dunkelberg, 1985), spends $\$ 5,000$ per position to hire (IHRIM, 2010), and loses six times a position's base salary for hiring the wrong person (Barron, Bishop, \& Dunkelberg, 1985). With all of these statistics in mind, it appears it is about time to take a critical look at the primary job selection device used to hire applicants in most organizations, the formal employment interview.

Besides the current turbulent economy playing a role in unemployment and frequent job changes, this study suggests that the formal employment interview may be failing employers and employees. They may not be the most effective tool in hiring the right person for the job. In this capitalistic society, there is a tendency to place more emphasis on a person's job skills than a person's values. This may be problematic if the job seeker's values are not congruent with the mission of the organization. As this research has shown, professionals placed high value on getting to know the values of the individuals they were involved with, and when they shared values with the potential candidate, they were more likely to offer them an internship.

More than $30 \%$ of internships turn into full-time jobs, as revealed in the literature review (Bryan, 2009). Even unemployed, experienced professionals are turning to 
internships as a means of getting a foot in the door during these tough economic times. Therefore, receiving an internship offer may be more significant than it appears. If informational interviews lead to internships, in part because they have allowed the participants to learn about shared values, this structural arrangement may demand more serious attention as a first step in the employment process. A more extensive study of candidates who secure employment positions after first going through an informational interview and internship, compared to those who are directly hired through a formal interview process, may provide additional information.

\section{Practical Suggestions for Employers}

For employers, the present study suggests getting to know job candidates beyond the "canned" answers that are often offered in a formal job interview. Most job candidates have prepared answers they hope an employer is looking for, making it difficult to assess them accurately beyond their job skills. Kirkwood and Ralston (1999) suggest that employers avoid following the advice of experts on interviewing and search for a more effective way to get to know job candidates. The findings from the present study suggest that employers or human resource personnel try to encourage an understanding at a deeper level with the job candidate. Some structural changes could be made, such as loosening up the time boundaries and not adhering to a strict question-andanswer format. Professionals charged with employing should strive to have a conversation with applicants. This will allow for the freedom to deviate from set questions and answers.

This study has also shown that reducing the fear of participants in order to share feelings and viewpoints is important-recognizing that this reciprocal sharing of 
information may lead to a deepened understanding of each other and an opportunity where both participants can more accurately assess job fit.

\section{Practical Suggestions for Job Seekers}

For job seekers, this study suggests the benefits of having an interview venue that promotes small talk. Incorporating one's values into one's answers allows a professional to obtain an understanding of an applicant beyond job skills and provides an opportunity to connect on a deeper level. The small talk that occurred during these informational interviews gave the professional and job seeker the opportunity to discover that they shared values, and the professional was likely to serve as an advocate for the job seeker.

Kirkwood and Ralston's (1999) research suggests that job applicants work on practicing "conscious transparency." Their findings indicate that job seekers should not be afraid to let professionals know they are passionate about a career field or that they value integrity and professionalism. This study concurs. When students made their values clear, professionals were able to recognize what they shared, and it prompted them to offer an internship.

This study also revealed several successful discourse strategies used by the students during their informational interviews that might hold value for others. Students used detailed examples to support answers to the professionals' questions. This allowed the professionals to gain a deeper understanding of the students. Students also asked the professionals other-directed questions such as "What challenges do you face in your job?" or "Do you find your job rewarding? If so, in what ways?" These questions not only showed interest but also were interpreted by the professionals as flattering, because they allowed them to share stories and details about their personal successes, challenges, and values. 
Professionals in this study cited the students' values as what prompted them to offer the students an internship. Therefore, job seekers should not hesitate to initiate small talk, share values, and ask detailed questions in an effort to understand the professional at a deeper level, and in turn, the professional may learn more about the job seeker.

\section{Advice for Educators}

This study implies that educators of business communication classes would be well-advised to share the following tips when teaching interviewing skills:

1. Share stories about yourself.

2. Share stories that support your values.

3. Ask other-centered questions to the interviewer when the opportunity arises.

As a professor of business communication, I regularly teach interviewing skills to my students, and I intend to change the manner in which I teach based on this study. I currently encourage my students to have prepared or "canned" answers to questions. I teach them how to answer questions effectively and what not to say. I now plan to encourage my students to open up more in their interviews and share detailed stories. I have always recommended they share stories, because I believe it makes a student memorable, but I have never really realized why stories make such a lasting impression on employers. Now I understand that the stories provide a way for the employers to get to know the job candidate at a deeper level. Though I will still encourage my students to have some ideas in mind on how to answer common interview questions, I will encourage them even more to have a pool of detailed stories ready to share that foster an understanding of themselves at a deeper level. 
Furthermore, as an educator, I plan to stress the importance of the student asking the interviewer more other-directed questions during or at the end of the formal job interview. Typically, an interviewer will ask the job applicant if he/she has any questions at the end of the interview, and I usually recommend my students ask more details about the position they are applying for, thus demonstrating their interest in the position. Due to the present study, I will now recommend my students ask questions that allow the interviewer to share his/her opinions or values as previously described. This not only leads to a sense of flattery for the interviewer, but also helps the student and interviewer establish co-membership.

\section{Future Areas of Research}

Throughout the course of doing research, collecting data, and analyzing data, I discovered many areas related to the connection between networking and securing employment that call for more research in the areas of 1) co-membership and values, 2) outlook for employment interview, and 3) the need for additional cases.

\section{Co-membership and Values}

Erickson and Schultz define co-membership as "relating to one another on the grounds of shared particularistic attributes of status (including ethnicity, race, but not limited to it)" (1982, p. 210). They elaborate on their definition by stating that it includes all of those things in common between counselor and student. They even distinguish between a high level of co-membership and a low level of co-membership, which is based on the number of similar attributes the counselor and student have in common. They do not, however, specifically mention "values" as one of these attributes. This study has shown that "values" should be considered a critical part of co-membership. Establishing a value-informed kind of connection led the professionals in this study to 
advocate on behalf of a student. Additional research should be conducted to assess more generally the strength of co-membership, particularly as it relates to values, and its impact on job offers.

\section{Outlook for Formal Employment Interviews}

This study suggests that the informational interview is a better way to get to know job candidates and assess job fit. Due to the limitations of formal interviews, the informational interview sheds light on many ways to improve the formal job interview in terms of interaction and structure. The formal interview structure needs extensive improvement. By attending to the lessons learned from this study regarding the benefits of informational interviews, employers, job seekers, and educators may be able to take steps to improve their search for the "right" candidate and for the "right" job.

\section{Additional Cases}

As previously mentioned, one limitation of this study was that it involved a small number of cases. The goal of this qualitative study, however, was not to derive a generalization based on a large number of participants. Instead, the goal was to take a step toward understanding informational interviews and their influence on job opportunities. Additional studies would be helpful in revealing more about when, how, and why they are successful and for whom.

While this study showed that there were no significant differences between males (including five male students and four male professionals) and females (including three female students and four female professionals) or across ethnic groups (all white, Caucasian participants), an examination of a broader sample of cases may give rise to some differences based on gender and ethnicity. This study can also be built upon by 
looking at more cases of informational interviews, wherein structural and interactional conditions may differ and where outcomes may not be so positive.

For instance, although the purpose of the informational interview is not to obtain an internship, it would be helpful to compare the differences between informational interviews wherein the same professional was interviewed by multiple students and extended an internship offer to one student and not the others. A study of this nature would allow for an understanding of what happens during the informational interview to advantage or disadvantage certain students.

To further test the value of informational interviews, research comparing internships generated after an informational interview and those generated from other sources would be useful in understanding if informational interviews provide a better opportunity for greater knowledge exchange and understanding of the other person, and thus more likelihood of success in obtaining an internship offer.

\section{Conclusion}

Three-fourths of jobs are filled through means other than formal interviews, and this study examined one way this was happening. I found, by looking closely at the structure and interactions that ensue during the informational interviews, that professionals and job candidates can rightly view these interviews as another important networking strategy.

This form of networking can serve to foster internship offers. This study has shown that a deep level of understanding can be achieved that results in positive outcomes for the student. By changing the rules of a traditional job search device, the formal interview, to one that more closely resembles an informational interview-a 
different structure with a different set of rules_-outcomes are more likely to be favorable for both the professional and the candidate.

Therefore, this study concludes that informational interviews, in some cases, create even more than a networking opportunity; they create a tool for employment. In an economic time where jobs are scarce, and more than $50 \%$ of employers are offering fulltime jobs to their interns (WSN, 2010), this study may lead more people to ask themselves if their "net" is working. 


\section{References}

Arthur, M. B., \& Rousseau, D. M. (Eds.). (1996). The boundaryless career: A new employment principle for a new organizational era. New York: Oxford University Press.

Baker, W. (2000). Achieving success through social capital: Tapping the hidden resources in your personal and business networks. San Francisco: Jossey-Bass.

Barron, J. M., Bishop, J., \& Dunkelberg, W. C. (1985). Employer search: The interviewing and hiring of new employees. Review of Economics \& Statistics, $67(1)$, pp. 43-52.

Bennis, W. (2000). Managing the dream. New York, NY: Harper-Collins.

Berger, P., \& Luckman, T. (1966). The social construction of reality: A treatise in the sociology of knowledge. Garden City, NewYork: Doubleday Press.

Bissonnette, Z. (2010). Is this the worst year to graduate ever? The Daily Beast. Retrieved from http://www.thedailybeast.com

Blumer, H. (1968). Symbolic interactionism. Englewood Cliffs, NJ: Prentice Hall.

Burg, B. (1998). Endless referrals. ( $3^{\text {rd }}$ Ed.). McGraw Hill: USA.

Burt, R. S. (2004). Structural holes and good ideas. American Journal of Sociology, $110(2), 349-399$.

Burt, R. S. (1998). The Gender of Social Capital. Rationality and Society.

Burt, R. S. (1992). Structural holes: The social structure of competition. Cambridge, MA: Harvard University Press.

Bryan, C. (2009, September). What to do after your internship is over (keeping up the momentum). The Emerging Professional. Retrieved from http://emergingprofessional.typepad.com/the_emerging_professional/2009/09/pos t-internship_momentum.html

Byrne, D. (1969). Attitudes and attraction. In L. Berkowitz (Ed.), Advances in experimental social psychology, 4, pp. 35-90. New York: Academic Press.

Byrne, D., \& Clore, G. L. Jr. (1967). Effectance arousal and attraction. Journal of Personality and Social Psychology, 6(4), whole number 48.

Byrne, D., \& Rhamey, R. (1965). Magnitude of positive and negative reinforcements as a determinant of attraction. Journal of Personality and Social Psychology, 2, 884889. 
Byrne, D., \& Wong (1962). Racial prejudice, interpersonal attraction, and assumed dissimilarity of attitudes, Journal of Abnormal and Social Psychology, 65, 246253.

Byrne, D., Young, R. K., \& Griffitt, W. (1966). The reinforcement properties of attitude statements. Journal of Experimental Research in Personality, 1, 266-276.

Collins, R. (1987). Interaction ritual chains, power, and property: The micro-macro connection as an empirically based theoretical problem. In J.C. Alexander, B. Giesen, R. Munch, \& N.J. Smelser (Eds.), The micro-macro link. (pp. 193-206). Berkeley, CA: University of California Press.

Crosby, O. (2002). Informational interviewing: Get the inside scoop on careers. Occupational Outlook Quarterly, 46(2), p. 32-37.

De Janasz, S.C., \& Forret, M.L. (2008). Learning the art of networking: A critical skills for enhancing social capital and career success. Journal of Management Education, 32(5), 629-650.

De Janasz, S. C., Sullivan, S. E., \& Whiting, V. (2003). Mentor networks and career success: Lessons for turbulent times. Academy of Management Executive, 17, 7893.

Ellis, A. P. J., West, B. J., Ryan, A. M., \& DeShon, R. P. (2002). The use of impression management tactics in structured interviews: A function of question type? Applied Psychology, 87(6), p. 1200-1208.

Erickson, F., \& Schultz, J. (1982). The counselor as gatekeeper: Social and cultural organization of communication in counseling interviews. New York, New York: Academic Press.

Forret M. L., \& Dougherty, T. W. (2004). Networking behaviors and career outcomes: Differences for men and women? Journal of Organizational Behavior, 25, 419437.

Forret, M. L., \& Dougherty, T. W. (2001). Correlates of networking behavior for managerial and professional employees. Group \& Organizational Management, $26,283-311$.

Garfinkel, H. (1967). Studies in ethnomethodology. Englewood Cliffs: NJ. Prentice-Hall.

Gerdes, L. (2009, January 27). Relevant work experience a must: say employers to recent grads. Bloomberg Businessweek. Retrieved from http://www.businessweek.com/managing/blogs/first jobs/archives/2009/01/releva nt_work_e_1.htm 
Gilmore, D. C., \& Ferris, G. R. (1989). The effects of applicant impression management tactics on interviewer judgments. Journal of Management, 15(4), 557-564.

Glesne, C. (2006). Becoming qualitative researchers. New York: Longmann.

Goldberg, C. B. (2005). Relational demography and similarity-attraction in interview assessments and subsequent offer decisions: Are we missing something? Group and Organization Management, 30, 597.

Hall, D. T. (2002). Careers in and out of organizations. Thousand Oaks, CA: Sage.

Hall, D. T. (1996). The career is dead-long live the career: A relational approach to careers. San Francisco: Jossey-Bass.

Harrison, D., Price, K., \& Bell, M. (1998). Beyond relational demography: Time and the effects of surface and deep-level diversity on work group cohesion. Academy of Management Journal, 41, 96-107.

Helgesen, S. (2005). The web of inclusion: Architecture for building great organizations. Beard Books: Washington, D.C.

Helgesen, S. (1995). The female advantage: Women's ways of leadership. $\left(2^{\text {nd }}\right.$ ed.) Doubleday: New York, NY.

Higgins, C. A., \& Judge, T. A. (2004). The effect of applicant influence tactics on recruiter perceptions of fit and hiring recommendations: A Field Study. Journal of Applied Psychology, 89(4), p. 622-632.

Higgins, M. C. (2000). The more, the merrier? Multiple developmental relationships and work satisfaction. Journal of Management Review, 26, 264-288.

Higgins, M. C., \& Kram, K. E. (2001). Constellations and careers: Toward understanding the effects of multiple developmental relationships. Journal of Organizational Behavior, 22, 223-247.

Hopko, Dr. R., Hunt, M. K., \& Aremento, M. E. A. (2005). Attentional task aptitude and performance anxiety. International Journal of Stress Management, 12(4), 389408.

HR World: Human Resources World (2011). Cost-per-hire calculator. Retrieved from http://www.hrworld.com/calculators/costperhire/

Hunter, J. E., \& Hunter, R. F. (1984). Validity and utility of alternative predictors of job performance. Psychological Bulletin, 96(1), 72-98.

IHRIM: International Association for Human Resources (2010). Job bank. Retrieved from http://ihrim.hrdpt.com/html/ats/ 
Jones, D. B., \& Pinkney, J. W. (1989). An exploratory assessment of the sources of jobinterview anxiety in college students. Journal of College Student Development, $30,553-560$.

Kirkwood, W. G., \& Ralston, S. M. (1999). Inviting meaningful applicant performances in employment interviews. Journal of Business Communication, 36(1), 55-76.

Koss-Feder, L. (1999, March 22). It's still who you know... in the boom economy, job hunting is a way of life. Here's how to do it. Time, 114F.

McCarthy, J., \& Goffin, R. (2004). Measuring job interview anxiety: Beyond weak knees and sweaty palms. Personnel Psychology, 57, 607-637.

McFarland, L. A., Ryan, A. M., \& Kriska, S. D. (2002). Field study investigation of applicant use of influence tactics in a selection interview. Journal of Psychology, $136(4), 383-398$.

Merriam, S. B. (2002). "Reflections on doing qualitative research" in Merriam, S. B. \& Associates (2002). Qualitative research in practice. San Francisco: Jossey-Bass.

Mulvaney, M. K. (2003). The information interview: Bridging college and beyond. Business Communication Quarterly, 66(3), p. 66-72.

NACE: National Association of Colleges and Employers (2009). Retrieved from http://naceweb.org/spotlight/2009/e030409a

Newcomb, T. M. (1961). The acquaintance process. New York: Holt, Rinehart, and Winston.

Normington, E. P. (2011). Internships: Want a higher paying first job? The High School Graduate. Retrieved from

http://www.thehighschoolgraduate.com/editorial/internships.htm

Owens, L.A., \& Young, P. (2008). You're hired! The power of networking. Journal of Vocational Rehabilitation, 29, pp. 23-28.

Posthuma, R. A., Morgeson, F. P., \& Campion, M. A. (2002). Beyond employment interview validity: A comprehensive narrative review of recent research trends over time. Personnel Psychology, (55), 1-81.

Patton, M. Q. (2002). Qualitative evaluation and research methods. Newbury Park, CA: Sage Publications.

Rand, T. M., \& Wexley, K. N. (1975). Demonstration of the effect, "similar to me," in simulated employment interviews. Psychological Reports, 36, 535-544. 
Reaser, L. (2010). Economic forecast. Speech presented at Point Loma Nazarene University May 15, 2009.

Remillard, B. (2009, October 12). What are the total costs of a bad hire? Retrieved from http://impacthiringsolutions.com/blog/tag/cost-of-bad-hire/

Schneider, B. (1987). The people make the place. Personnel Psychology, 40, 437-453.

Strauss, A., \& Corbin, J. (1990). Basics of qualitative research: Grounded theory procedure and techniques. $\left(2^{\text {nd }}\right.$ ed.). Newbury Park, California: Sage.

Sullivan, S. E. (1999). The changing nature of careers: A review and research agenda. Journal of Management, 25, 457-484.

Thompson, D. (2010, April 16). California jobless rate swells to 12.6 percent. Associated Press. Retrieved from http://www.google.com/hostednews/ap/article

Triandis, H. C. (1959). Cognitive similarity and interpersonal communication in industry. Journal of Applied Psychology, 43, 321-326.

Tsai, W. C., Chen, C. C., Chiu, S. F. (2005). Exploring boundaries of the effects of applicant impression management tactics in job interviews. Journal of Management, 3I(1), 108-125.

Turner, R. H. (2005). Role-taking process versus conformity. In D. Brisset \& C. Edgley (Eds.) Life as theater: A dramaturgical sourcebook. (pp. 85-99). Brunswick, NJ: Transaction Publishers.

United States Department of Labor. (2010). Bureau of Labor Statistics economic new release: Employment situation summary. Retrieved from http://www.bls.gov/news.release/empsit.nr0.htm

Wayne, S. J., \& Kacmar, K. M. (1991). The effects of impression management on the performance appraisal process. Organizational Behavior and Human Decision Process, 48, 70-88.

Wiseman, P. (2010, January 8). Outlook for job market is grim. USA Today. Retrieved from http://www.usatoday.com/money/economy/employment/201001-07-future-job-prospects_N.htm

WSN: Washington Square News Editorial Board (2010, September 14). Tough economy means internships more important than ever. Washington Square News. Retrieved from $h t t p: / / n y u n e w s . c o m / o p i n i o n / 2010 / 09 / 14 / 15$ house/

Young, M. J., Behnke, R. R., \& Mann, Y. M. (2004). Anxiety patterns in employment interviews. Communication Reports, 17(1), 49-57. 
Yuen, J. (1998). Creative ways for managing workplace tension. Communication World, (15), 18-20. 


\section{Appendix A}

Email to Former Students 


\section{Appendix A}

\section{Email to Former Students}

Hello Former Bus. 213 Students,

If you are receiving this e-mail, you were a student in my Business 213 course last semester. As part of that class, you conducted informational interviews with business professionals. Upon completion of your interviews, several of you mentioned that you received internship offers.

The purpose of this e-mail is to find out if those of you who received internship offers through your informational interview would be willing to participate in a study I am conducting as part of my doctoral studies at University of San Diego. The purpose of the study is to learn more about your informational interview experience, your view of how an informational interview differs from a formal employment interview, and conditions of the context that you feel may have led to an internship offer.

Participation is completely voluntary. Pseudonyms will be utilized to ensure confidentiality.

Please respond to me by e-mail within the next two weeks if you would like to participate in this study.

Thank you,

Kim Hogelucht 
Appendix B

Email to Business Professionals 


\section{Appendix B}

\section{Email to Business Professionals}

Hello (insert name),

My name is Kim Hogelucht. I am a professor of business communication at Point Loma Nazarene University. I want to first thank you for allowing (insert student's name) the opportunity to conduct an informational interview with you. This opportunity provides my students with invaluable insight into the career field of their choice. I thank you for being part of this experience.

Secondly, I was wondering if you would be willing to take part in a study regarding informational interviews. I am conducting this study as part of my doctoral work at University of San Diego. In addition to the students' perspectives, I feel the study would greatly benefit from sharing a professional's perspective on informational interviews, specifically, how the informational interview differs from a formal employment interview and how an informational interview may lead to an internship offer.

Please note that your participation is completely voluntary. For confidentiality purposes, pseudonyms will be used.

If you choose to participate, please respond to me by e-mail within two weeks.

I thank you for your time and consideration.

Sincerely,

Kim Hogelucht 
Appendix C

Interview Guide for Students 


\section{Appendix C \\ Interview Guide for Students}

1. Can you tell me about your informational interview experience?

2. How many informational interviews did you conduct?

3. How many internship offers did you receive?

4. Was there anything about the informational interview context that you think helped to foster an internship offer?

5. What surprised you the most about your informational interview experience?

6. What would you compare your informational interview experience to? Can you think of an analogy or similar experience?

7. When you called to set up your informational interview, how much time did you ask for? How long did your informational interview last? Why?

8. Have you ever been interviewed for a job? If so, how do you think an informational interview differs from a formal employment interview? 


\section{Appendix D}

Interview Guide for Professionals 


\section{Appendix D}

Interview Guide for Professionals

1. Tell me about your informational interview experience with (student's name)?

2. What did it feel like being interviewed about your job?

3. Were you comfortable sharing information about your job? Explain.

4. What information did you want to share with (student's name)?

5. (Student's name) revealed that an opportunity to do an internship surfaced in his/her informational interview with you? Can you tell me more about how this opportunity surfaced?

6. Do you think that having conducted an informational interview with you put (student's name) at an advantage for obtaining an internship?

7. How much time did the student ask for? Do you recall how long the interview lasted? Explain

8. Did you have any connection to Point Loma Nazarene before this informational interview?

9. What is the process for obtaining an internship with your company?

10. Is there a possibility that an internship could turn into a full time job down the road?

11. Have you ever interviewed job candidates for an opening? If so, how would you say an informational interview differs from a formal interview (when you're interviewing someone)? Structure? Interaction?

12. Any advice for students interested in conducting informational interviews?

13. Any advice for professionals considering taking part in an informational interview? 
Appendix E

Informational Interview Assignment 


\section{Appendix E}

\section{Informational Interview Assignment}

Informational Interview Assignment (100 pts.) This written and oral assignment is designed to help you gain valuable information about your future career. This assignment involves four parts:

1. Locate interviewees/schedule interviews. Start on this right away, today. Schedule an interview with three people who are currently employed in the industry/profession you think you would ideally like to pursue. Shoot for the stars with this assignment. You may not interview close friends, family members, PLNU employees, or current employers (these are all fairly easy access for you/ you should do these interviews outside of this assignment). Instead, research your field and shoot for the top in your field. Students in the past have used the directory of PLNU contacts/alumni as a resource (I will give this to you), friends' parents and parents' friends, yellow pages, and lastly some students went directly to the organization they were interested in to inquire about a possible informational interview. All three interviews need to take place face to face. I cannot stress this enough, as the entire process is such a learning experience (from dressing up, to traveling to the individual's workplace, to having a face to face conversation, to experiencing the organizational culture). You are missing out on too much if you try and do this over the phone. Points will be deducted if a face to face interview is not conducted for at least the three required interviews as this requires much more time and effort than interviewing over the phone. The exception: When you have completed your three face to face interviews, you may do one over the phone (if at a great distance and an outstanding resource). You would then have four interviews to report on.

2. Conduct the interviews. Conduct the three 20 minute interviews at the professionals' workplaces. Avoid meeting at unusual settings and at late hours. Check with me if you are questioning anything. Consider carefully the image you want to project in both dress and style. Always lean toward the conservative side in dress. Make sure you ask for a business card before you leave the interview.

3. On the day $1^{\text {st }}$ day of presentations, all class members will turn in the following:

a. One typed page (double-spaced) with three paragraphs highlighting:

1) How your career goal is clearer, has changed or been adapted because of what you learned from this assignment.

2) What you learned from the process of conducting interviews.

3) What advice you would give to people doing this assignment in the future.

b. One copy of each of the thank you letters you sent to interviewees and 
a copy of the addressed, stamped envelope to each interviewee. Each thank you should be different in that you should highlight something specific you learned from each person. You may type or write these. If you write them, make sure your writing is legible.

4. Deliver a Presentation. The fourth part of the assignment is a 8-10 minute Informative Power Point presentation about the industry or field you researched. The format of the verbal presentation is as follows: Informational Interview Presentation Format

I. Introduction

A. Attention-getter (interesting story, rhetorical question, etc.)

B. Area you are interested in/ career field

C. Preview of points covered in body (for each interview, mention name, title, and lesson learned from each person/keep this brief as you'll go into detail in body.

II. Body

A. Career field/occupation \#1

1. Name of person interviewed/ company's name/ rational for choosing this professional and company/ how you discovered this professional (list I gave you, parents' friends, etc.)

a. background information on company and position

b. position and skills needed/incorporate specific stories from interviewee.

2. Lesson learned from interview

a. State lesson clearly, i.e. "Every day is different"

b. Tell detailed/specific story to support lesson

B. Career field/ occupation \#2

1. Name of person interviewed/ company's name/ rational for choosing this professional and company/ how you discovered this professional (list I gave you, parents' friends, etc.)

a. background information on company and position

b. position and skills needed/incorporate specific stories from interviewee.

2. Lesson learned from interview

a. State lesson clearly i.e. "Customer Service is Key"

b. Tell detailed/specific story to support lesson

C. Career field/ occupation \#3

1. Name of person interviewed/ company's name/ rational for choosing this professional and company/ how you discovered this professional (list I gave you, parents' friend, etc.)

a. background information on company and position

b. position and skills needed/incorporate specific stories from interviewee.

2. Lesson learned from interview

a. State lesson clearly i.e. "Advanced Education is Vital"

b. Tell detailed/specific story to support lesson 


\section{Conclusion}
A. Summary of main points (mention each professional and lesson learned from each briefly)
B. State how this assignment has influenced your career goals.
For example, what occupation are you leaning toward now, are your career goals clearer, etc.
C. Tie back creatively to your attention-getter (i.e. repeat opening rhetorical question and creatively answer it).




\section{Appendix F}

The Shaping and Re-Shaping of Structure and Interaction 


\section{Appendix F}

The Shaping and Re-Shaping of Structure and Interaction

\section{The Shaping and Re-Shaping of Structure and Interaction}
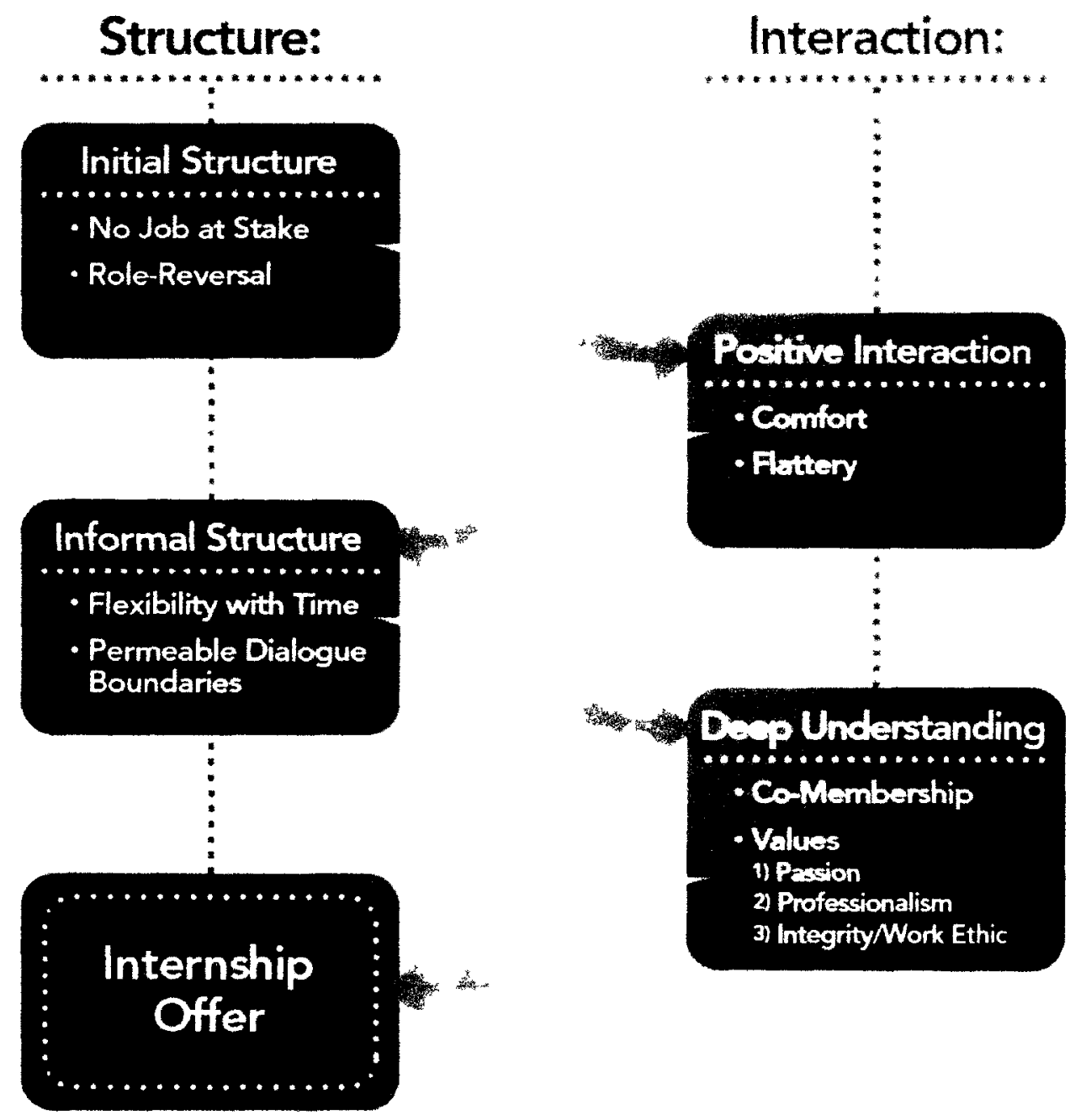

Figure 1. The shaping and re-shaping of structure and interaction 